\title{
Dopaminergic Stimulation Leads B-cell Infiltration into the Central Nervous System upon Autoimmunity
}

\section{Carolina Prado}

Fundacion Ciencia Para la Vida

\section{Francisco Osorio-Barrios}

Fundacion Ciencia Para la Vida

\section{Alexandra Espinoza}

Fundacion Ciencia Para la Vida

\section{Juan J Saez}

Pontificia Universidad Catolica de Chile

\section{María I Yuseff}

Pontificia Universidad Catolica de Chile

Rodrigo Pacheco ( $\nabla$ rpacheco@cienciavida.org )

Fundacion Ciencia Para la Vida https://orcid.org/0000-0001-8057-9806

\section{Research article}

Keywords: regulatory B lymphocytes, antigen-presenting cells, chemokine receptors, neuroinflammation, experimental autoimmune encephalomyelitis, central nervous system homing

Posted Date: May 25th, 2021

DOl: https://doi.org/10.21203/rs.3.rs-41605/v3

License: (c) (i) This work is licensed under a Creative Commons Attribution 4.0 International License. Read Full License

Version of Record: A version of this preprint was published at Journal of Neuroinflammation on December 1st, 2021. See the published version at https://doi.org/10.1186/s12974-021-02338-1. 


\section{Abstract}

Background. Recent evidence has shown dopamine as a major regulator of inflammation. Accordingly, dopaminergic regulation of adaptive and innate immune cells plays an important role in the physiopathology of inflammatory disorders. Multiple sclerosis (MS) is an inflammatory disease involving a $\mathrm{CD}^{+}{ }^{+} \mathrm{T}$-cell-driven autoimmune response to central nervous system (CNS) derived antigens. Evidence from animal models has suggested that B-cells play a fundamental role as antigen-presenting cells (APC) re-stimulating $\mathrm{CD} 4^{+}$T-cells in the CNS as well as regulating T-cell response by mean of inflammatory or anti-inflammatory cytokines. Here we addressed the role of the dopamine receptor D3 (DRD3), which display the highest affinity for dopamine, in B-cells in animal models of MS.

Methods. Mice harbouring Drd3-deficient or Drd3-suficient B-cells were generated by bone marrow transplantation into recipient mice devoid of B-cells. In these mice we compare the development of experimental autoimmune encephalomyelitis (EAE) induced by immunization with a myelin oligodendrocyte glycoprotein (MOG)-derived peptide (pMOG), a model that leads to CNS-autoimmunity irrespective of the APC function of B-cells, or by immunization with full-length human MOG protein (huMOG), a model in which antigen-specific activated B-cells display a fundamental APCs function in the CNS.

Results. Our data shows that, by promoting the expression of the chemokine receptor CXCR3 in autoreactive B-cells, DRD3-stimulation favours the CNS-tropism in a subset of B-cells that act as APC in the CNS, which is fundamental for disease development. Furthermore, we found that DRD3- stimulation induced the expression of the CNS-homing molecule CD49d in a B-cell subset with anti-inflammatory features, thus attenuating EAE manifestation in a CNS-autoimmunity model independent of the APC function of B-cells.

Conclusions. Our findings demonstrate that DRD3-stimulation in B-cells exerts a dual role in CNSautoimmunity, favouring CNS-tropism of pro-inflammatory B-cells with APC function, and also promoting CNS-homing of B-cells with anti-inflammatory features. Thus, these results show DRD3-signalling in Bcells as a key regulator of CNS-autoimmunity.

\section{Background}

Multiple Sclerosis (MS) is a chronic inflammatory disorder involving an autoimmune response to the central nervous system (CNS) characterized by demyelination, axonal degeneration and gliosis [1, 2]. Several studies have consistently shown a major role of $\mathrm{CD} 4^{+}$T-cells leading the damage of the CNS, whereas the involvement of B-cells in the pathogenesis of MS was attributed for many years just to autoantibody production [3]. Nevertheless, current successful therapeutic approaches based on B-cell depletion have motivated to invest efforts in understanding the role of B-cells in the pathophysiology of MS [4-7]. Accordingly, recent evidence has suggested that, in addition to the production of autoantibodies, B-cells might play an important role in the initiation of neuroinflammation in animal 
models of MS. A number of studies performed in mice have indicated that B-cells play an important role as antigen-presenting cells (APC) in the CNS, which is required for the re-stimulation of autoreactive Tcells infiltrating the target tissue [4, 8-11]. Moreover, another group of studies has shown that B-cells participate as potent regulators of inflammation providing both pro-inflammatory or immunosuppressive cytokines. Of note, the production of regulatory cytokines by B-cells might be induced by the recognition of autoantigens or by mechanisms independent of Ag-recognition [11-14].

The main animal model to study MS is the experimental autoimmune encephalomyelitis (EAE), for which there are many variants. Two different EAE variants have been used to study different features of B-cells in MS, which differ in the nature of the autoantigen $[15,16]$. The first one is induced by immunization with a short peptide derived from the myelin oligodendrocyte glycoprotein ( $\left.\mathrm{MOG}_{35-55} ; \mathrm{PMOG}\right)$, in which B-cells play only a regulatory role, immunosuppressive at early-stage and pro-inflammatory at late-stage [12]. In this model B-cells are activated independent of the B-cell receptor (BCR) specificity. Although in the pMOG-induced EAE model B-cells are capable of presenting short peptides through direct binding to cell surface MHC-II molecules, their APC-function is irrelevant in comparison with other APCs, such as dendritic cells (DCs) and macrophages [11]. The second EAE model is induced by immunization with the full-length human MOG protein (huMOG), in which antigen-specific activated B-cells display a fundamental APCs function in the CNS, and also provide significant pro-inflammatory cytokines and participate as a source of antibody-producing plasma cells [11, 17-19].

Recently, dopamine has emerged as a major regulator of inflammation by stimulating dopamine receptors (DRs) in innate and adaptive immune cells $[20,21]$. Remarkably, the stimulation of low-affinity DRs, including DRD1 and DRD2, by high levels of dopamine has shown to exert anti-inflammatory effects in sepsis [22], Parkinson's disease [23, 24], inflammatory bowel diseases [25, 26] and MS [27, 28]. Conversely, low dopamine levels, through the stimulation of high-affinity DRs, including DRD3, DRD4 and DRD5, have shown to promote inflammation in animal models of Parkinson's disease [29-32], inflammatory bowel diseases [33, 34], allergic asthma [35] and MS [36-39]. Interestingly, increased dopamine levels have been detected in the striatum during the peak of EAE manifestation [40]. Moreover, the dopaminergic system has been found to be altered in both innate and adaptive immune system in MS patients $[37,41,42]$. Since the reduction of striatal dopamine has been shown to induce an earlier onset of the disease and to increase EAE severity [43], it is likely that dopaminergic signalling through highaffinity DRs in immune cells infiltrating the brain might play a regulatory role in CNS autoimmunity. According to this possibility, previous studies have addressed the role of DRD5 in DCs and CD4 ${ }^{+} \mathrm{T}$-cells. DRD5-signalling in DCs potentiated IL-12 and IL-23 production, thereby promoting Th1 and Th17 mediated autoimmunity in the CNS [37-39]. In addition, DRD5-signalling in CD4 ${ }^{+}$T-cells exerted a dual role in the physiopathology of EAE, potentiating early inflammation mediated by effector T-cells, but exacerbating suppressive activity in Treg cells and thereby dampening disease manifestation in late EAE stages [36]. Although dopaminergic signalling through DRD3, which display the highest affinity for dopamine, has been strongly associated with the development and progression of inflammatory 
affections $[29,33,34,44,45]$, the involvement of this receptor in the physiopathology of MS/EAE remains poorly explored.

Despite B-cells play an important role in the physiopathology of MS [7] and constitute one of the leukocyte population with the highest levels of DRs expression [46], the role of dopaminergic-stimulation in B-cells in CNS autoimmunity has not been yet studied. Indeed, B-cells have been shown to express the highest levels of DRD3 [31, 46], whose stimulation has been strongly associated to inflammation [47]. Here we addressed the role of DRD3-stimulation in the adaptive immune system in CNS autoimmunity. Our findings indicate that DRD3-stimulation in $\mathrm{CD} 4^{+} \mathrm{T}$-cells was irrelevant in EAE, whilst DRD3-stimulation in B-cells exerted fundamental regulatory processes in CNS autoimmunity. Mechanistic analysis revealed a dual role of DRD3-stimulation in B-cells, promoting CNS tropism of B-cells with APC-potential, and favouring the infiltration of regulatory (suppressive) B-cells into the CNS.

\section{Methods}

Animals. Six- to eight- week-old male or female mice of the C57BL/ 6 background were used in all

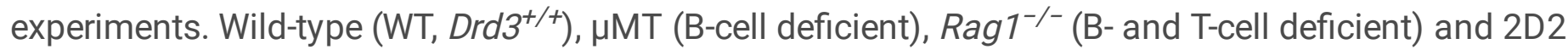
(bearing the transgenic TCR specific for the $\mathrm{MOG}_{35-55}$ peptide on $\mathrm{IA}^{\mathrm{b}}$ molecules; $T C R^{\mathrm{MOG}}$ ) mice were purchased from The Jackson Laboratory (Bar Harbor, ME). DRD3-knockout ( $\mathrm{Prd}^{-/-}$) mice were kindly donated by Dr. Marc Caron [48] and B6.SJL.PTPRC $\left(\mathrm{Cd} 45.1^{+/+}, \mathrm{Drd}^{+/+}\right)$mice were kindly donated by Dr. Maria Rosa Bono [49]. Transgenic 2D2 $\mathrm{Drd}^{-/-}$mice were generated by crossing parental mouse strains.

Generation of mixed bone-marrow chimera mice. Mice harbouring Drd3-deficiency in specific cell populations were generated using the mixed bone-marrow (BM) chimera system as described previously $[14,50]$. Briefly, Rag $1^{-/}$or $\mu \mathrm{MT}$ mice were irradiated with $1100 \mathrm{cGy}$-irradiation (Cs source) and 24h later received the i.v. transfer of a mix of donor BM cells from indicated mouse strains ( $10^{7}$ total BM cells per recipient mouse). Before EAE experiments, chimeric mice were left untreated for 8 weeks to let the hematopoietic system to reconstitute the peripheral lymphoid system, as described before [36]. To restrict the genetic Drd3-deficiency to B- and T-cells, irradiated $\mathrm{Rag}^{-/-}$mice received a BM mix composed of $80 \%$ from $\operatorname{Rag} 1^{-/-}$mice and $20 \%$ from $\mathrm{Drd3}^{-/-}$mice. The control group received a BM mix composed of $80 \%$ from $\operatorname{Rag}^{-/-}$mice and $20 \%$ from $\mathrm{Drd}^{+/+}$mice. Thus, all B- and T-cells were originated from the $\mathrm{Drd}^{-/-}$ (or $\mathrm{Drd}^{+/+}$in the control group) BM. On the other hand, the 4:1 ratio $\left(\operatorname{Rag} 1^{-/-}\right.$-to-Drd3 ${ }^{-/-}$or $\operatorname{Rag}^{-/ /}$-to$\operatorname{Drd}^{+/+}$) in the donor BM [51] ensure that all the other hematopoietic lineages different from lymphocytes were predominantly originated from the $\operatorname{Rag}^{-/-} \mathrm{BM}$, and therefore were Drd3 sufficient. To restrict genetic Drd3-deficiency only to B-cells, irradiated $\mu \mathrm{MT}$ mice received a BM mix composed of $80 \%$ from $\mu \mathrm{MT}$ mice and $20 \%$ from $\mathrm{Drd}^{-/-}$mice. The control group received a BM mix composed of $80 \%$ from $\mu \mathrm{MT}$ mice and $20 \%$ from $\mathrm{Drd}^{+/+}$mice. Thus, all B-cells were originated from the $\mathrm{Drd}^{-/-}$(or $\mathrm{Drd}^{+/+}$in the control group) BM, whilst all the other hematopoietic lineages were predominantly originated from the $\mu \mathrm{MT}$ BM. FACS analysis confirmed hematopoietic reconstitution of sub-lethally irradiated mice. In some 
experiments, mixed BM chimera mice were generated by reconstituting irradiated $\mu \mathrm{MT}$ mice with a BM mix from B6.SJL.PTPRC $\mathrm{Drd}^{+/+}\left(\mathrm{Cd} 45.1^{+/+}\right)$mice and BM from $\mathrm{Drd}^{-/-}$mice $\left(\mathrm{Cd} 45.2^{+/+}\right)$at 50-to-50 or 30-to-70 ratios.

EAE induction and evaluation. Experimental mice were s.c. immunized with $50 \mu \mathrm{g}$ myelin oligodendrocyte glycoprotein 35-55 peptide $\left(\mathrm{pMOG}_{35-55}\right.$; Genetel Laboratories, Madison, WI) or $100 \mu \mathrm{g}$ human MOG protein (huMOG; Anaspec) emulsified in CFA (Invitrogen) supplemented with heat-inactivated Mycobacterium tuberculosis H37 RA (Difco Laboratories, Detroit, MI). In addition, mice received the i.p. administration of $500 \mathrm{ng}$ pertussis toxin (Calbiochem, La Jolla, CA) on days 0 and 2. In primary progressive EAE experiments, $24 \mathrm{~h}$ before disease induction $\mathrm{Rag}^{-/-}$mice received the i.v. transfer of $7,5 \times 10^{5}$ splenic naïve (CD25- $\left.\mathrm{CD} 44^{-} \mathrm{CD} 62 \mathrm{~L}^{+}\right) \mathrm{CD} 4^{+}$T-cells purified from $\mathrm{Drd}^{+/+}$or $\mathrm{Drd}^{-/-} 2 \mathrm{D} 2$ transgenic mice. Clinical manifestation was assessed daily according to the following scoring criteria: 0 , no detectable signs; 1 , flaccid tail; 2 , hind limb weakness or abnormal gait; 3 , complete hind limb paralysis; 4 , paralysis of fore and hind limbs; and 5, moribund or death.

The animals were included in the study when they underwent successful pMOG-CFA or huMOG-CFA immunization, defined by the formation of a sub-cutaneous emulsion at the site of injection. The animals were excluded: i. when leakage of the emulsion was observed during injection, ii. when infections or diseases unrelated to the experiment were detected, or when the animal died prematurely (usually less than $0.5 \%$ of the animals), avoiding the collection of disease severity data.

For the isolation of CNS mononuclear cells, mice were perfused through the left cardiac ventricle with cold PBS. The brain and spinal cord were dissected, and CNS tissue was minced into small pieces and digested by collagenase D (2.5 mg/ml; Roche Diagnostics) and DNase I $\left(1 \mathrm{mg} / \mathrm{ml}\right.$; Sigma) at $37^{\circ} \mathrm{C}$ for 45 min. Digested tissue was filtered through a $70 \mu \mathrm{m}$ cell strainer obtaining single cell suspension that was subjected to centrifugation in a Percoll gradient (70\%/30\%). Mononuclear cells were removed from the interphase and resuspended in culture medium for further analysis.

Antibodies and Flow cytometry analysis. For all analyses, live/dead discrimination was assessed using Zombie Aqua (ZAq) Fixable Viability kit (Biolegend). Spleens were minced until reach a cell-suspension and then red blood cells were lysed using Ammonium-Chloride-Potassium (ACK) buffer. Fluorochromeconjugated mAb specific to mouse CD45 (clone 30-F11), CD19 (clone 6D5), IgD (clone 11-26c.2a), IgM (clone RRM-1), CXCR3 (clone CXCR3-A3), CD49d (clone R1-2), Tbet (clone 4B10), CD4 (clone GK-1.5), IFNy (clone XMG1.2), IL-17 (clone TC11-18H10.1), GM-CSF (clone MP1-22E), CD20 (clone SA275A11), MHC-II (clone M5/114.15.2), CD21/CD35 (clone 7E9), CD1d (clone 1B1), CD5 (clone 53-73), CD23 (clone B3B4), CD138 (clone 281-2), CD44 (clone IM7), TCRß (clone B183983), CD11c (clone N418), CD3 (clone 1452C11), CD8 (clone 58 - 6,7), CD11b (clone M1/70), F4/80 (clone BM8), Ly6G (clone 1A8), CD45.1 (clone A20) and CD45.2 (clone 104) were purchased from Biolegend and to mouse FoxP3 (clone FJK-16s) from eBioscience. To analyse dopamine receptor D3 (DRD3) expression, a polyclonal rabbit anti-mouse DRD3 (ab42114) and a polyclonal rabbit IgG (isotype control for DRD3 staining, ab171870) were purchased from Abcam; secondary goat anti-rabbit IgG-PE (50-8036) was obtained from TONBO Biosciences. For 
intracellular immunostaining, cells were first labeled with antibodies specific for cell-surface markers and then fixed and permeabilized with FoxP3 Fixation/Permeabilization kit (eBioscience). Afterwards, FoxP3 immunostaining or intracellular cytokine immunostaining was performed in permeabilized cells followed by flow cytometry analysis. For analysis of cytokine production, cells were re-stimulated with ionomycin (Sigma) and PMA (Sigma) in the presence of brefeldin A (Invitrogen) during $5 \mathrm{~h}$ before immunostaining. All immunostaining were performed for $30 \mathrm{~min}$ at $4^{\circ} \mathrm{C}$. To quantify the absolute number of cells, $50 \mu \mathrm{L}$ of 123 count eBeads (Thermofisher Scientific) was added to each sample prior to analysis by flow cytometry and cell concentration was calculated using the following formula:

\section{Cell Concentration $($ Cells $/ m L)=\frac{\text { Cell Count } \times \text { eBead Volume }}{\text { eBead Count } \times \text { Cell Volume }} \times$ eBead Concentration}

Data were collected with a FACSCanto II (BD) and results were analysed with FACSDiva (BD) and FlowJo software (Tree Star).

In vitro B-cell culture. Splenic naïve B-cells (TCRB $\left.{ }^{-} C D 11 c^{-} C D 19^{+} \lg D^{\text {hi }} \lg M^{\text {int }}\right)$ were isolated by cell-sorting from $\mathrm{Drd}^{+/+}$or $\mathrm{Drd}^{-/-}$mice. When proliferation was determined, naïve B-cells were loaded with $5 \mu \mathrm{M}$ Cell trace violet (CTV; Invitrogen, Carlsbad, CA, USA) before stimulation. Cells were stimulated with 10 $\mu \mathrm{g} / \mathrm{mL}$ of goat anti-mouse $\operatorname{lgM~F}(\mathrm{ab})^{\prime}{ }_{2}$ fragments (eBioscience); $1 \mu \mathrm{g} / \mathrm{mL}$ anti-CD40 (clone $1 \mathrm{C} 10$; Biolegend); $1 \mu \mathrm{M}$ CpG DNA (ODN 1824; InvivoGen) and $10 \mathrm{ng} / \mathrm{mL}$ IFN- $\gamma$ (Peprotech) for $5 \mathrm{~d}$. Then, Tbet and CXCR3 expression was determined by flow cytometry analysis. The extent of cell death was quantified using the ZAq Fixable Viability kit (Biolegend).

In vitro Antigen presentation assays. huMOG protein or $\mathrm{pMOG}_{35-55}$ were coupled to glutaraldehydeactivated amino beads ( $40 \times 10^{6}$ beads for $20 \mu \mathrm{g}$ huMOR or $\mathrm{PMOG}$ ) together with $\mathrm{F}\left(\mathrm{ab}^{\prime}\right) 2$ anti-mouse-IgM fragments in equal concentrations, as previously described [52]. Splenic CD 19+ B-cells were sorted from $\mathrm{Drd3}^{+/+}$or $\mathrm{Drd3}^{-/-}$animals and then incubated with huMOG- or $\mathrm{PMOG}_{35-55^{-}}$coated beads in a B-cell-tobead ratio $1: 1$ for $5 \mathrm{~h}$ at $37^{\circ} \mathrm{C}$ to allows the uptake and processing of antigens. Afterwards, B-cells were washed and then incubated with MOG-specific CD $4^{+}$T-cells at B-cell-to-T-cell ratio 1:5 for 5 days. For each point, $10^{5} \mathrm{CD}^{+}$2D2 T-cells loaded with Cell Trace Violet (Invitrogen) were used. Proliferation and production of cytokines were evaluated by FACS analysis.

Real-Time Quantitative PCR. Total RNA was extracted from cells using the Total-RNA EZNA kit (Omega Bio-Tek). The RNA was DNase-digested using the TURBO DNA-free kit (Ambion) and then used to synthesize cDNA catalysed by the M-MLV reverse transcriptase (Life Technologies). Quantitative geneexpression analysis was performed using Brilliant II SYBR Green QPCR Master Mix (Agilent). Expression of target genes was normalized to the levels of gapdh transcripts and multiplied by an arbitrary factor. i/10 Forward 5'-GAA GAC AAT AAC TGC ACC CA-3'; i/10 Reverse 5'- CAA CCC AAG TAA CCC TTA AAG TC3'; il6 Forward 5'-AGG ATA CCA CTC CCA ACA GAC CT-3'; il6 Reverse 5'-CAA GTG CAT CGT TGT TCA TAC3'; csf2 Forward 5'-ACC ACC GCG GAT TTC AT-3'; csf2 Reverse 5-TCA TTA CGC AGG CAC AAA AG-3'; 
gapdh Forward 5'- TCC GTG TTC CTA CCC CCA ATG-3'; gapdh Reverse 5'- GAG TGG GAG TTG CTG TTG AAG-3'.

Statistical analyses and sample size estimation. Sample size was estimated with the mean and dispersion obtained from preliminary data using the sample size calculator:

https://www.stat.ubc.ca/ rollin/stats/ssize/n2.html. A power of $80 \%$ was assumed. All values are expressed as the mean \pm SEM. Statistical analysis were performed with two-tailed unpaired Student's $t$ test when comparing only two groups and with one-way ANOVA followed by Tukey's post-hoc test when comparing more than two groups with only one variable (treatment or genotype). To analyse differences in experiments comparing different genotypes and different treatments, two-way ANOVA followed by Sidak's post-hoc test was performed. All analyses were carried out using the GraphPad Prism 6 Software. $P$ values $<0.05$ were considered significant.

\section{Results}

\section{DRD3-stimulation in the adaptive immune system is required to the development of CNS autoimmunity}

To address the role of DRD3 in the adaptive immune system in the development of CNS autoimmunity we generated chimeric mice bearing Drd3-deficient adaptive immune system and Drd3-sufficient innate immune system. For this purpose, recombination-activating gene 1 knockout $\left(\operatorname{Rag1^{-/}}\right)$ mice, which are devoid of $\mathrm{T}$ and $\mathrm{B}$ lymphocytes, were $\mathrm{\gamma}$-irradiated with a myeloablative dose and then received the transfer of donor bone marrow (BM) obtained from $\operatorname{Rag} 1^{-/-}$mice and $D r d 3^{-/-}$mice mixed in a 4:1 ratio Rag 1 ${ }^{-/-}$-to-Drd3 ${ }^{-/-}$as described before [51]. Thus, after BM reconstitution, Drd3-deficiency was confined to $T$ and $B$ lymphocytes, whilst non-lymphocytic hematopoietic cells were mostly originated from Drd3sufficient $\left(\operatorname{Rag~}^{-/-}\right)$BM. The control group of mice, harbouring Drd3-sufficient adaptive immune system, received the transfer of $\mathrm{BM}$ obtained from $\operatorname{Rag}^{-/-}$mice $(80 \%)$ and $\mathrm{Drd}^{+/+}$mice $(20 \%)$. Eight weeks after BM-transfer, experimental autoimmune encephalomyelitis (EAE) was induced and the extent of disease severity was evaluated throughout the time-course of disease development. The results show that EAE manifestation was abrogated in mice bearing Drd3-deficient adaptive immune system (Fig. 1A), indicating that DRD3 in T and/or B lymphocytes was required for EAE development. Of note, DRD3signalling in $\mathrm{CD}^{+}{ }^{+}$-cells has been shown to promote inflammation in animal models of Parkinson's disease [29-31] and inflammatory bowel diseases [33,34]. Accordingly, we next evaluated the role of DRD3 in autoreactive CD4 ${ }^{+}$T-cells in a mouse model of primary-progressive multiple sclerosis (MS). To this end, $24 \mathrm{~h}$ before EAE induction, Rag $^{-/-}$mice received the transfer of naïve $\mathrm{CD} 4^{+} \mathrm{T}$-cells isolated from Drd3-deficient or Drd3-sufficient 2D2 transgenic mice, which express a transgenic TCR specific for the $\mathrm{MOG}_{35-55}$ peptide (pMOG) on IA ${ }^{\mathrm{b}}$ molecules [53]. The results show that mice receiving Drd3-deficient or Drd3-sufficient CD 4 ${ }^{+}$T-cells developed EAE with similar kinetics and severity (Fig. 1B), thus ruling out a relevant role of DRD3 in $\mathrm{CD}^{+}{ }^{+}$T-cells in the development of CNS autoimmunity. We next attempted to 
determine the role of DRD3-stimulation in B-cells, which have been associated with the production of proinflammatory and anti-inflammatory cytokines in EAE [12] and have been involved as key APC in the development of CNS autoimmunity [11]. Accordingly, to analyse the protective and pathogenic potential DRD3-stimulation in B-cells in CNS autoimmunity, we used two EAE models, which differ in the nature of the autoantigen and display differential B-cell involvement: i. the EAE model independent of the APCfunction of B-cells, which is induced by immunization with PMOG; and ii. the EAE model dependent of the APC-function of B-cells, which is induced by immunization with huMOG. In this regard, we first compared the time-course of clinical manifestation, and the extent of DRD3 expression and B-cell frequency in relevant tissues when EAE was induced by immunization of WT mice with PMOG or huMOG. The results show EAE manifestation was similar in both models, although the peak of severity was higher in huMOGinduced EAE than PMOG-induced EAE (Fig. 1C). In addition, in both models B-cells frequency was significantly reduced in the spleen and the CNS, whereas it remained unchanged in the cervical lymph nodes (CNS draining lymph nodes; dLN) during the peak of disease manifestation (Fig. 1D). Interestingly, the frequency of DRD3-expression was selectively increased in B-cells infiltrating the CNS upon huMOGinduced EAE but not upon pMOG-induced EAE (Fig. 1E). Conversely, the percentage of DRD3-expression was reduced in a similar extent in dLN and splenic B-cells in both EAE models (Fig. 1E; see the gating strategy for the analysis of DRD3 expression in figure S1A). Interestingly, the density of DRD3 expression in B-cells infiltrating the CNS was selectively reduced upon pMOG-induced but not in huMOG-induced EAE (Fig. S1B-C). Nonetheless, the density of DRD3 expression was reduced in those B-cells circulating through peripheral blood and the spleen upon both PMOG-induced or huMOG-induced EAE (Fig. S1B-C). Further analysis of DRD3-expression in different B-cells subsets indicated that DRD3 upregulation observed in B-cells infiltrating the CNS upon huMOG-EAE occurred selectively in $\mathrm{CD}_{20} \mathrm{O}^{+} \mathrm{MHC}-\mathrm{II}^{+} \mathrm{B}-\mathrm{cells}$ (Fig. S2D), which display APC function [11]. In addition to $\mathrm{CD} 20^{+} \mathrm{MHC}-\mathrm{II}^{+} \mathrm{B}-\mathrm{cells}$, we found that $\mathrm{CD} 21^{+}$ $\mathrm{CD}_{23}{ }^{+} \operatorname{lgM}^{+} \mathrm{B}$-cells, which have been described to exert suppressive function [54], was the only B-cell subset expressing detectable levels of DRD3 upon pMOG-induced EAE in the CNS and dLN (Fig. S2B-D). Taken together, these results suggest that DRD3-stimulation in B-cells plays an important role in the development of CNS autoimmunity, involving different B-cell subsets depending on the nature of the antigen.

\section{Drd3-deficiency in B-cells exacerbates disease severity in an EAE model that does not depend on the APC- function of B-cells}

To confirm the relevance of DRD3 in B-cells in CNS autoimmunity, we next generated mice harbouring Drd3-deficiency restricted only to B-cells. For this purpose, $\mu \mathrm{MT}$ mice, which are devoid of B-cells [55], were $\mathrm{y}$-irradiated with a myeloablative dose and then received the i.v. transfer of mixed BM progenitors coming from $\mu \mathrm{MT}(80 \%)$ and $\mathrm{Drd}^{-/-}$or $\mathrm{Drd}^{+/+}(20 \%)$ mice (Fig. 2A). Since B-cells arose from $\mathrm{Drd}^{-/-}$ BM progenitors and all the other cells arose predominantly from $\mu \mathrm{MT}$ BM progenitors in mice bearing $\mu \mathrm{MT} / \mathrm{Drd}^{-/-} \mathrm{BM}\left(\mu \mathrm{MT} / \mathrm{Drd}^{-/-} \rightarrow \mu \mathrm{MT}\right.$ mice$)$ after reconstitution of the haematopoietic system, Drd3deficiency was restricted to B-cells in these mice. Conversely, all haematopoietic system was $\mathrm{Drd}^{+/+}$in control mice bearing $\mu \mathrm{MT} / \mathrm{Drd}^{-+/+} \mathrm{BM}\left(\mu \mathrm{MT} / \mathrm{Drd}^{+/+} \rightarrow \mu \mathrm{MT}\right.$ mice) (Fig. 2A). Of note, the frequencies of 
the main leukocyte populations were equivalent in BM chimera mice containing either $\mathrm{Drd} 3^{+/+}$or $\mathrm{Drd}^{-/-}$ B-cells (Fig. S3). Using these chimeric mice, we first attempted to determine the relevance of DRD3 in Bcells in CNS autoimmunity in a model that does not depend on the APC-function of B-cells. Accordingly, EAE was induced with pMOG in $\mu \mathrm{MT} / D r d 3^{-/-} \rightarrow \mu \mathrm{MT}$ and $\mu \mathrm{MT} / D r d 3^{+/+} \rightarrow \mu \mathrm{MT}$ mice and the disease severity as well as the phenotype of $\mathrm{CD} 4^{+} \mathrm{T}$-cells infiltrating the CNS were determined at the peak of disease manifestation. The results show that EAE severity was significantly higher in $\mu \mathrm{MT} / \mathrm{Drd}^{-/-} \rightarrow \mu \mathrm{MT}$ mice when compared with control $\mu \mathrm{MT} / \mathrm{Drd}^{+/+} \rightarrow \mu \mathrm{MT}$ mice (Fig. $2 \mathrm{~B}$ ). According to the exacerbated disease manifestation, $\mu \mathrm{MT} / \mathrm{Drd}^{-/-} \rightarrow \mu \mathrm{MT}$ mice displayed increased frequency of CD $4^{+} \mathrm{T}$-cells producing GM-CSF in the CNS (Fig. 2C-D), which has been described to be the most inflammatory cytokine promoting neuroinflammation in EAE [56]. Conversely, no significant alterations were detected in the phenotype of peripheral CD4 ${ }^{+}$T-cells when compared both experimental groups of mice (Fig. $2 \mathrm{E}$ ). Thus, these results together indicate that DRD3-signalling in B-cells limits the generation of CD $4^{+} \mathrm{T}$-cells producing GM-CSF in the CNS and consequently attenuates disease manifestation in a model independent of the APC-function of B-cells.

\section{DRD3 in B-cell is required for disease manifestation in an EAE model that depends on the APC-function of B-cells}

We next evaluated the role of DRD3 in B-cells in a model of CNS autoimmunity that depends on the APCfunction of B-cells. To this end, EAE was induced in $\mu \mathrm{MT} / \mathrm{Drd}^{-/-} \rightarrow \mu \mathrm{MT}$ and $\mu \mathrm{MT} / \mathrm{Drd} 3^{+/+} \rightarrow \mu \mathrm{MT}$ mice (Fig. 2A) using huMOG and disease severity as well as the extent of T-cell infiltration into the CNS were analysed. Strikingly, Drd3-deficiency in B-cells abolished EAE manifestation (Fig. 3A). According to this result, we observed that $D r d 3$-deficiency resulted in a sharp reduction of the frequency of inflammatory CD4 ${ }^{+}$T-cells in the CNS, including Th1, Th17 and GM-CSF producers CD4 ${ }^{+}$T-cells (Fig. 3B-C).

Nevertheless, the frequency of different $\mathrm{CD} 4^{+} \mathrm{T}$-cell subsets in the periphery was not altered by Drd3deficiency in B-cells (Fig. 3D). Taken together these results provide evidence that DRD3-stimulation in Bcells plays a pro-inflammatory role in a model of CNS autoimmunity that depends on the APC-function of B-cells, favouring the participation of inflammatory CD4 ${ }^{+}$T-cells in the CNS and, thereby, promoting disease development.

\section{DRD3-signalling favours the expression of a4-integrin and increases the infiltration of immunosuppressive B-cells into the CNS in an EAE model that does not depend on the APC-function of B- cells}

Next, we attempted to determine the mechanism by which DRD3 in B-cells exerts a suppressive effect on the development of CNS autoimmunity in a model independent of the APC-function of B-cells. Since Drd3deficency in B-cells affected the T-cell response only in the CNS, but not in the spleen (Fig. 2D-E), we addressed the possibility that DRD3-stimulation was affecting B-cell migration into the CNS. In this regard, both a4-integrin (CD49d) and the chemokine receptor CXCR3 [57] have been involved in the infiltration of B-cells into the CNS upon autoimmunity. Accordingly, EAE was induced with PMOG in 
$\mu \mathrm{MT} / \mathrm{Drd}^{-/-} \rightarrow \mu \mathrm{MT}$ and $\mu \mathrm{MT} / \mathrm{Drd}^{+/+} \rightarrow \mu \mathrm{MT}$ mice and the extent of a4-integrin and CXCR3 expression was quantified in B-cells infiltrating the CNS and the spleen (see the gating strategy in Figure S4). Whereas similar levels of a4-integrin and CXCR3 expression was detected in splenic B-cells, a significant and selective reduction in the frequency and density of a4-integrin expression was observed in B-cells infiltrating the CNS from $\mu \mathrm{MT} / D r d 3^{-/-} \rightarrow \mu \mathrm{MT}$ mice when compared with $\mu \mathrm{MT} / \mathrm{Drd} 3^{+/+} \rightarrow \mu \mathrm{MT}$ mice (Fig. 4A-C). These results suggest that B-cell infiltration into the CNS may be impaired upon pMOGinduced EAE. Next, we addressed the possibility that DRD3 was regulating B-cell infiltration into the CNS upon PMOG-induced EAE. For this purpose, using congenic donor mice $\left(\mathrm{Cd} 45.1^{+/+} / \mathrm{Cd} 45.2^{-/-} / \mathrm{Drd} 3^{+/+}\right.$and Cd45.1 $1^{-/-} / \mathrm{Cd} 45.2^{+/+} / \mathrm{Drd}^{-/-}$mice) we generated chimeric BM mice harbouring both Drd3-sufficient and Drd3-deficient B-cells (Fig. 4D). In these animals, EAE was induced with PMOG and the extent of B-cells from different genotypes was compared in the CNS as well as in the spleen and peripheral blood. Interestingly, whereas the frequency of Drd3-sufficient B-cells was increased in peripheral blood and the CNS upon EAE development, the frequency of Drd3-deficient B-cells remained unaltered in all tissues evaluated upon EAE-development (Fig. 4E). Moreover, the analysis of absolute numbers of B-cells revealed that in healthy conditions Drd3-deficiency resulted in a reduction in the number of B-cells circulating through peripheral blood and the spleen, but without effect in the CNS. Conversely, upon EAE development, Drd3-deficiency induced a selective decrease in the number of B-cells infiltrating the CNS, and without effect in the number of B-cells circulating through peripheral blood and the spleen (Fig. S5). To explore whether the differences observed between Drd3-sufficient and Drd3-deficient B lymphocytes in the frequency and number of cells infiltrating the different tissues analysed were due an effect of DRD3 in proliferation or cell death, we performed experiments in which B-cell activation was induced in $\mathrm{Drd} 3^{+/+}$ or $\mathrm{Drd}^{-/-} \mathrm{CD} 19^{+}$cells and the extent of proliferation and viability were determined. The results showed that Drd3-deficiency resulted in a slight increase in B-cell proliferation and without effect in cell death (Fig. 4F-G), thereby ruling out the possibility that the reduction of cell number or frequency of Drd3deficient B-cells in the CNS was due to impaired proliferation or increased cell death. Thus, these results suggest that Drd3-deficiency in B-cells results in reduced a4-integrin expression and, consequently, in impaired B-cell infiltration into the CNS upon PMOG-induced EAE. Since our results associated DRD3 to the B-cell subset $\mathrm{CD} 21^{+} \mathrm{CD} 23^{+} \mathrm{IgM}^{+}$(Fig. S2B-D), which exerts anti-inflammatory activity in the CNS in the PMOG-induced EAE model (Fig. 2), we reasoned that Drd3-deficiency should result in accumulation of suppressive B-cells in the spleen. Accordingly, we next sought to confirm the nature of cytokine produced by Drd3-deficient and Drd3-sufficient B-cells retained in the periphery in this EAE model. For this purpose, at the peak of pMOG-induced EAE manifestation, CD 45. $1^{+}$and CD $45.2^{+}$B-cells were isolated from the spleen by cell-sorting and the transcripts encoding for pro-inflammatory and anti-inflammatory cytokines were quantified by qRT-PCR. The results show that Drd3-deficiency in B-cells results in exacerbated i/10 transcription and reduced expression of the mRNA encoding for GM-CSF (Fig. 4H). Taken together, these results indicate that DRD3 in B-cells is required to induce full CNS-tropism in B-cells with antiinflammatory activity in a model of CNS autoimmunity that is independent of the APC-function of B-cells.

DRD3-stimulation in B-cell favours the CXCR3 expression and their infiltration into the CNS in an EAE model that depends on the APC-function of B-cells

Page 10/28 
Finally, we attempted to determine the mechanism by which DRD3-stimulation in B-cells exerts a proinflammatory effect in the development of CNS autoimmunity in a model dependent of the APC-function of B-cells. Since our results show that disease manifestation was completely abrogated in mice harbouring Drd3-deficient B-cells in this animal model, we next evaluated the role of DRD3 in the ability of B-cells to act as APC. Accordingly, EAE was induced in $\mu \mathrm{MT} / D r d 3^{-/-} \rightarrow \mu \mathrm{MT}$ and $\mu \mathrm{MT} / \mathrm{Drd} 3^{+/+} \rightarrow \mu \mathrm{MT}$ mice using huMOG and at the peak of disease manifestation the extent of class II MHC expression was evaluated in splenic B-cells, nevertheless no significant differences were found between both experimental groups (Fig. S6A-B). Furthermore, the APC ability of $\mathrm{Drd3}^{+/+}$and $\mathrm{Drd}^{-/-}$B-cells was evaluated in vitro using huMOG-coupled beads as antigen and CD4 ${ }^{+}$T-cells expressing a MOG-specific TCR as described before [52]. The results show that Drd3-deficiency in B-cells did not affect neither T-cell proliferation nor T-cell differentiation (Fig. S6C-D), thus ruling out the possibility that DRD3 was relevant for APC-function of B-cells upon huMOG-induced EAE. Since Drd3-deficency in B-cells affected the T-cell response only in the CNS, but not in the spleen (Fig. 3B-D) upon huMOG-induced EAE, we addressed the possibility that DRD3-stimulation was affecting B-cell migration into the CNS in this model. Accordingly, EAE was induced with huMOG in $\mu \mathrm{MT} / \mathrm{Drd}^{-/-} \rightarrow \mu \mathrm{MT}$ and $\mu \mathrm{MT} / \mathrm{Drd}^{+/+} \rightarrow \mu \mathrm{MT}$ mice and the extent of a4integrin and CXCR3 expression was quantified in B-cells infiltrating the CNS and the spleen (see the gating strategy in Figure S4). The results show that Drd3-deficiency in B-cells resulted in increased frequency of CXCR3 expression in the spleen and reduced CXCR3 expression in the CNS, without effect in a4-integrin expression in any tissue (Fig. 5A-C). Thus, these results suggest that B-cell infiltration into the CNS may be impaired by Drd3-deficiency upon huMOG-induced EAE.

Afterwards, we addressed the possibility that DRD3 was regulating B-cell infiltration into the CNS upon huMOG-induced EAE. For this purpose, using congenic donor mice $\left(\mathrm{Cd} 45.1^{-/-} / \mathrm{Cd} 45.2^{+/+} / \mathrm{Drd}^{-/-}\right.$and Cd45. $1^{+/+} / \mathrm{Cd} 45.2^{-/-} / \mathrm{Drd}^{+/+}$mice) we generated chimeric BM mice harbouring both Drd3-sufficient and Drd3-deficient B-cells (Fig. 5D). Because the transfer of $\operatorname{Drd}^{+/+}$to-Drd3 ${ }^{-/-}$BM at the 1:1 ratio resulted in decreased Drd3-defficient B-cells in steady state (Fig. 4D-E), in these experiments we carried out the transfer of $\mathrm{Drd3}^{+/+}$to-Drd3 ${ }^{-/-} \mathrm{BM}$ at 3:7 ratio. In these animals, EAE was induced with huMOG and the extent of B-cells from different genotypes was compared in the CNS as well as in the spleen and peripheral blood. The results show that frequency of Drd3-sufficient B-cells was significantly increased in the CNS upon EAE development, whilst it was not changed in Drd3-deficient B-cells (Fig. 5E). On the other hand, whereas the frequency of $D r d 3^{-/-}$B-cells was higher than $D r d 3^{+/+}$B-cells in the periphery upon steady-state, only $\mathrm{Drd3}^{-/-} \mathrm{B}$-cells were reduced in frequency in peripheral blood and the spleen upon huMOG-induced EAE (Fig. 5E). Thus, these results suggest that Drd3-deficiency in B-cells results in altered CXCR3 expression and thereby impaired B-cell infiltration into the CNS upon huMOG-induced EAE. To gain a deeper mechanistic insight of the role of DRD3 in CXCR3 expression on B-cells, we performed in vitro B-cell activation assay induced by anti-CD40, anti-IgM, IFNY and the TLR9-ligand CpG [58-60]. Since CXCR3 expression is dependent on the activity of the transcription factor Tbet in B-cells [61], we activated naïve B-cells isolated from $\mathrm{Drd}^{+/+}$and $\mathrm{Drd}^{-/-}$mice and the extent of CXCR3 and Tbet expression was determined by flow cytometry. The results show that Drd3-deficiency resulted in reduced frequency and 
density of CXCR3 expression without effect on Tbet expression (Fig. 5F-G), thus indicating that DRD3stimulation promotes CXCR3 expression down-stream Tbet action. Together these results indicate that DRD3-stimulation promotes CXCR3 expression on pro-inflammatory B-cells and the consequent infiltration into the CNS upon huMOG- induced EAE.

\section{Discussion}

Our findings demonstrated an important role of dopaminergic stimulation mediated by DRD3 in promoting the infiltration of pro-inflammatory and anti-inflammatory B-cells in the CNS in two different animal models of CNS autoimmunity.

Interestingly our data shows that frequency of DRD3 ${ }^{+}$B-cells was selectively increased in the CNS upon huMOG-induced EAE. Further phenotypical analysis shows that the only B-cell population expressing DRD3 in the CNS in this EAE model was the $\mathrm{CD} 20^{+} \mathrm{MHC}-\mathrm{II}^{+}$subset. A previous study shows that this $\mathrm{B}-$ cell population exerts a fundamental function as APC in the CNS upon huMOG-induced EAE [11]. Nevertheless, it is important to consider that MHC-Il expression in B-cells is also required for the production of T-cell dependent autoantibodies [62-64]. According to the fundamental function of $\mathrm{CD} 2 \mathrm{O}^{+}$ $\mathrm{MHC}-\mathrm{II}^{+} \mathrm{B}$-cells in CNS autoimmunity and to the important role of DRD3 favouring the infiltration of these B-cells in the CNS, Drd3-deficiency in B-cells abrogated disease manifestation completely and strongly reduced the frequency of inflammatory $\mathrm{CD} 4^{+} \mathrm{T}$-cells in this animal model (Fig. 3 ).

Our mechanistic analysis showed that DRD3 was not necessary for APC function of B-cells, but was required to induce an efficient CNS tropism in this B-cell subset. This DRD3-induced CNS tropism was mediated by an up-regulation of CXCR3 expression. According to these findings, a recent study showed that B-cells expressing CXCR3 were enriched in the CNS of MS patients [61]. Moreover, the treatment of MS patients with a clinically effective drug, natalizumab, which avoids lymphocytes infiltration into the CNS, decreased the accumulation of $\mathrm{CXCR}^{+} \mathrm{B}$-cells into the CNS [61]. Interestingly, IFNy might induce the expression of the transcription factor Tbet, which promotes the expression of CXCR3 in lymphocytes, including B-cells. This chemokine receptor confers responsiveness to the chemokines CXCL9, CXCL10 and CXCL11, which are produced at high levels in sites of inflammation in response to IFNY [65]. Our results showed that Drd3-deficiency in B-cells attenuated the expression of CXCR3 without effects in the level of Tbet expression, indicating that DRD3 in B-cells favours CXCR3 expression downstream Tbet.

Using a model of CNS autoimmunity in which the APC function of B-cells is irrelevant, we found another important regulatory effect of DRD3 in the control of B-cell function. Our data shows that Drd3-deficiency in B-cells resulted in exacerbated disease manifestation and increased frequency of CD $4^{+}$T-cells producing GM-CSF in the CNS upon pMOG-induced EAE. Of note, it has been demonstrated that GM-CSF is the most pro-inflammatory cytokine produced by CD4 $4^{+}$T-cells in the CNS. In contrast to IL-17 and IFNy, GM-CSF is essential to promote EAE manifestation [56]. Thereby, our results suggested that DRD3stimulation favoured the function of B-cells with anti-inflammatory activity in the CNS. In this regard, three different subsets of B-cells with immunosuppressive function have been described so far, including 


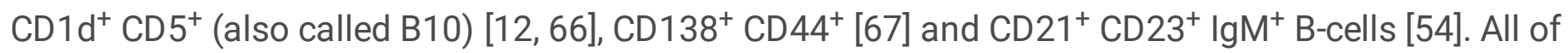
these subsets of regulatory B-cells exert immunosuppressive effects, attenuating the T-cell-mediated inflammation, which is mediated by IL-10. Interestingly, we observed that $\mathrm{CD} 21^{+} \mathrm{CD} 23^{+} \mathrm{IgM}{ }^{+}$was the only subset of regulatory B-cells detectable in the CNS upon pMOG-induced EAE, whilst $C D 1 \mathrm{~d}^{+} \mathrm{CD} 5^{+}$and $\mathrm{CD} 138^{+} \mathrm{CD} 44^{+}$subsets were barely detectable in these conditions. In addition, $\mathrm{CD} 21^{+} \mathrm{CD} 23^{+} \mathrm{IgM}{ }^{+} \mathrm{B}$-cells were the only subset of regulatory B-cells expressing detectable levels of DRD3 on the cell surface upon pMOG-induced EAE. Further analysis showed that DRD3 was necessary to induce the upregulation of a4integrin (CD49d) on the cell surface and the subsequent B-cell infiltration into the CNS upon pMOGinduced EAE. Importantly, the a4-integrin together $\beta 1$-integrin (CD29) form a heterodimeric complex on the lymphocyte surface that recognizes its ligand, the vascular cell adhesion protein 1 (VCAM-1) expressed in the blood-brain barrier, allowing the lymphocyte infiltration into the CNS $[68,69]$. It is noteworthy that the genetic deficiency of a4-integrin restricted to the $\mathrm{CD}_{19}{ }^{+} \mathrm{B}$-cells, resulted in exacerbated CNS autoimmunity in a model of PMOG-induced EAE [70], indicating the high relevance of a4-integrin in the infiltration of regulatory B-cells into the CNS in this EAE model. Accordingly, our results showed that Drd3deficiency in B-cells not only resulted in impaired a4-integrin expression and reduced B-cell infiltration into the CNS, but also in the accumulation of B-cells displaying immunosuppressive potential (higher i/10 and lower $c f s 2$ transcription) in the periphery.

Although the PMOG-induced EAE model represents a useful experimental system to study the regulatory role of B-cells irrespective to their APC function in the CNS, it seems that the huMOG-induced EAE model mimics better the B-cell participation in MS. According to this notion, it has been shown that natalizumab, an anti-a4-integrin monoclonal antibody, exerts an efficient therapeutic effect reducing disease manifestation in relapsing remitting MS patients $[57,71]$. Agree with this observation in human patients, mice harbouring a4-integrin-deficient B-cells display a significant reduction in disease manifestation upon huMOG-induced EAE model [69]. In contrast to the results observed in MS patients, the genetic deficiency of a4-integrin in B-cells resulted in exacerbated disease manifestation in a pMOG-induced EAE model [70]. Another aspect supporting the idea that huMOG-induced EAE is a proper experimental system to study Bcell participation in MS is based on CXCR3. According to the relevant role of CXCR3 in the infiltration of inflammatory B-cells observed here upon huMOG-induced EAE, CXCR3 has been found highly expressed on B-cells obtained from the CSF, meninges and brain of MS patients [57, 61]. In addition, the treatment of patients with natalizumab, which exerts an efficient therapeutic effect, reduced the accumulation of $\mathrm{CXCR3}^{+} \mathrm{B}$-cells into the CNS [61].

Dopaminergic signalling has been previously involved in the control of migration of other cells of the immune system. A recent study described that DRD4-stimulation induced an up-regulation of CCR5 in human macrophages and thus increasing their migratory ability to infiltrate the brain [72]. Conversely, signalling through DRD1 was identified as a negative regulator of CCR5 expression [72]. According to these results, the inhibition of dopamine synthesis induced by a-methylparatyrosine resulted in a decreased recruitment of peripheral monocytes into the nigrostriatal pathway in a mouse model of Parkinson's disease [73]. In addition, addressing the role of dopamine in the migration of lymphocytes,

Page 13/28 
Watanabe et al. have provided pharmacologic evidence suggesting that DRD3-signalling favours $C D 8^{+} \mathrm{T}-$ cell migration in response to CCL19, CCL21 and CXCL12 [74]. According to the role of CCR7 (receptor for CCL19 and CCL21) in the recirculation of naïve T-cells into the lymph nodes throughout the body, the systemic antagonism of DRD3 decreased the recruitment of naïve CD8 ${ }^{+}$T-cells into the lymph nodes [74]. Moreover, another work provided pharmacologic evidence supporting the notion that DRD5-signalling reduces CCR4 expression in Treg and thereby, attenuates the recruitment of these cells to CCL22 [75]. In addition, we recently found that DRD3-signalling down-regulates CCR9 expression on Treg, thus limiting their recruitment into the inflamed gut mucosa and consequently exacerbating inflammatory colitis [34]. Here, we provide in vivo evidence using genetic approaches demonstrating that DRD3 in B-cells mediates the up-regulation of CXCR3 and a4-integrin, thus affecting the recruitment of important B-cell subsets into the CNS upon the development of CNS autoimmunity.

\section{Conclusions}

Our findings demonstrate here for the first time how dopaminergic stimulation in B-cells exerts an important regulation in the development of CNS autoimmunity. First, by the stimulation of DRD3, dopamine favours CNS-tropism in a pro-inflammatory B-cell subset with APC function, thus contributing to the re-stimulation of encephalitogenic effector $\mathrm{CD} 4^{+} \mathrm{T}$-cells and thereby reinforcing CNS autoimmunity. Secondly, when B-cells with APC function are negligible, DRD3-stimulation promotes CNS-homing of Bcells with anti-inflammatory features and, consequently, dampening the T-cell mediated autoimmunity.

\section{Abbreviations}

Ammonium-Chloride-Potassium, ACK; Antibody, Ab; Antigen-presenting cells, APC; B-cell receptor, BCR; Bone marrow, BM; Central Nervous System, CNS; Cluster of differentiation $n, \mathrm{CD} n$; dendritic cells, DCs; draining lymph nodes, dLN; Dopamine Receptor, DR; DR D n, DRD $n$; Experimental Autoimmune Encephalomyelitis, EAE; human MOG, huMOG; mean fluorescence intensity, MFI; myelin oligodendrocyte glycoprotein, MOG; multiple sclerosis, MS; peptide $\mathrm{MOG}_{35-55}$, $\mathrm{PMOG}$; peripheral blood mononuclear cells, PBMC; recombination activating gene 1, Rag1; regulatory T-cells, Tregs; T-box transcription factor encoded by TBX21, Tbet; T helper $n$, Th $n$; vascular cell adhesion molecule 1, VCAM-1.

\section{Declarations}

\section{Ethics approval and consent to participate}

All procedures and housing were compliant with the recommendations in the $8^{\text {th }}$ edition of the Guide for the Care and Use of Laboratory Animals and with the United States Public Health Service Policy. The protocol was approved by the IACUC of Fundación Ciencia \& Vida (Permit Number: P009-2019).

\section{Consent for publication}


Not applicable

\section{Availability of data and materials}

The datasets used and/or analysed during the current study are available from the corresponding author on reasonable request.

\section{Competing interests}

The authors declare that they have no competing interests.

\section{Funding}

This work was supported by “Programa de Apoyo a Centros con Financiamiento Basal” AFB-170004 (to Fundación Ciencia \& Vida) and grants FONDECYT-3160383 (to C.P.) and FONDECYT-1210013 (to R.P.) from "Comisión Nacional de Investigación Científica y Tecnológica de Chile".

\section{Authors' contributions}

C.P. and R.P. designed the study, C.P, F.O.B, A.E. and J.J.S. conducted experiments and acquired data, C.P and R.P. analysed data, M.I.Y. provided new reagents, C.P and R.P. wrote the manuscript. All authors read and approved the final manuscript.

\section{Acknowledgements}

We thank Miss María José Fuenzalida for her technical assistance in cell-sorting and Dr. Sebastián Valenzuela for his valuable veterinary assistance in our animal facility. We thank Dr. Marc Caron for providing $\mathrm{Drd}^{-/-}$mice.

\section{References}

1. Claes N, Fraussen J, Stinissen P, Hupperts R, Somers V. B Cells Are Multifunctional Players in Multiple Sclerosis Pathogenesis: Insights from Therapeutic Interventions. Front Immunol. 2015;6:642.

2. Lehmann-Horn K, Kronsbein HC, Weber MS. Targeting B cells in the treatment of multiple sclerosis: recent advances and remaining challenges. Ther Adv Neurol Disord. 2013;6:161-73.

3. Linington C, Bradl M, Lassmann H, Brunner C, Vass K. Augmentation of demyelination in rat acute allergic encephalomyelitis by circulating mouse monoclonal antibodies directed against a myelin/oligodendrocyte glycoprotein. Am J Pathol. 1988;130:12.

4. von Budingen HC, Palanichamy A, Lehmann-Horn K, Michel BA, Zamvil SS. Update on the autoimmune pathology of multiple sclerosis: B-cells as disease-drivers and therapeutic targets. Eur Neurol. 2015;73:238-46.

5. Hauser S, Waubant E, Arnold D, Vollmer T, Antel J, Fox R, Bar-Or A, Panzara M, Sarkar N, Agarwal S, et al. B-Cell Depletion with Rituximab in Relapsing-Remitting Multiple Sclerosis. N Engl J Med. 
2008;358:13.

6. Hawker K, O'Connor P, Freedman MS, Calabresi PA, Antel J, Simon J, Hauser S, Waubant E, Vollmer T, Panitch $\mathrm{H}$, et al. Rituximab in patients with primary progressive multiple sclerosis: results of a randomized double-blind placebo-controlled multicenter trial. Ann Neurol. 2009;66:460-71.

7. Sabatino JJ Jr, Probstel AK, Zamvil SS. B cells in autoimmune and neurodegenerative central nervous system diseases. Nat Rev Neurosci. 2019;20:728-45.

8. Parker Harp CR, Archambault AS, Sim J, Shlomchik MJ, Russell JH, Wu GF. B cells are capable of independently eliciting rapid reactivation of encephalitogenic CD4 T cells in a murine model of multiple sclerosis. PLoS One. 2018;13:e0199694.

9. Pierson ER, Stromnes IM, Goverman JM. B cells promote induction of experimental autoimmune encephalomyelitis by facilitating reactivation of T cells in the central nervous system. J Immunol. 2014;192:929-39.

10. Parker Harp CR, Archambault AS, Sim J, Ferris ST, Mikesell RJ, Koni PA, Shimoda M, Linington C, Russell JH, Wu GF. B cell antigen presentation is sufficient to drive neuroinflammation in an animal model of multiple sclerosis. J Immunol. 2015;194:8.

11. Molnarfi N, Schulze-Topphoff U, Weber MS, Patarroyo JC, Prod'homme T, Varrin-Doyer M, Shetty A, Linington C, Slavin AJ, Hidalgo J, et al: MHC class Il-dependent B cell APC function is required for induction of CNS autoimmunity independent of myelin-specific antibodies. J Exp Med 2013, 210.

12. Matsushita T, Yanaba K, Bouaziz JD, Fujimoto M, Tedder TF. Regulatory B cells inhibit EAE initiation in mice while other B cells promote disease progression. J Clin Invest. 2008;118:3420-30.

13. Lehmann-Horn K, Kinzel S, Weber MS. Deciphering the Role of B Cells in Multiple Sclerosis-Towards Specific Targeting of Pathogenic Function. Int J Mol Sci 2017, 18.

14. Barr TA, Shen P, Brown S, Lampropoulou V, Roch T, Lawrie S, Fan B, O'Connor RA, Anderton SM, BarOr A, et al. B cell depletion therapy ameliorates autoimmune disease through ablation of IL-6producing B cells. J Exp Med. 2012;209:1001-10.

15. Marta CB, Oliver AR, Sweet SA, Pfeiffer SE, Ruddle NH. Pathogenic myelin oligodendrocyte glycoprotein antibodies recognize glycosylated epitopes and perturb oligodendrocyte physiology. Proc Natl Acad Sci U S A. 2005;102:6.

16. Oliver AR, Lyon GM, Ruddle NH. Rat and human myelin oligodendrocyte glycoproteins induce experimental autoimmune encephalomyelitis by different mechanisms in C57BL/6 mice. J Immunol. 2003;171:7.

17. Clements CSRH, Beddoe T, Tynan FE, Perugini MA, Johns TG, Bernard CC, Rossjohn J. The crystal structure of myelin oligodendrocyte glycoprotein, a key autoantigen in multiple sclerosis. Proc Natl Acad Sci U S A. 2003;100:6.

18. Hausler D, Hausser-Kinzel S, Feldmann L, Torke S, Lepennetier G, Bernard CCA, Zamvil SS, Bruck W, Lehmann-Horn K, Weber MS. Functional characterization of reappearing B cells after anti-CD20 treatment of CNS autoimmune disease. Proc Natl Acad Sci U S A. 2018;115:9773-8. 
19. Weber MS, Prod'homme T, Patarroyo JC, Molnarfi N, Karnezis T, Lehmann-Horn K, Danilenko DM, Eastham-Anderson J, Slavin AJ, Linington C, et al. B-cell activation influences T-cell polarization and outcome of anti-CD20 B-cell depletion in central nervous system autoimmunity. Ann Neurol. 2010;68:369-83.

20. Pacheco R, Contreras F, Zouali M. The dopaminergic system in autoimmune diseases. Front Immunol. 2014;5:117.

21. Vidal PM, Pacheco R. Targeting the Dopaminergic System in Autoimmunity. J Neuroimmune Pharmacol 2019.

22. Torres-Rosas R, Yehia G, Pena G, Mishra P, del Rocio Thompson-Bonilla M, Moreno-Eutimio MA, Arriaga-Pizano LA, Isibasi A, Ulloa L. Dopamine mediates vagal modulation of the immune system by electroacupuncture. Nat Med. 2014;20:291-5.

23. Shao W, Zhang SZ, Tang M, Zhang XH, Zhou Z, Yin YQ, Zhou QB, Huang YY, Liu YJ, Wawrousek E, et al. Suppression of neuroinflammation by astrocytic dopamine D2 receptors via alphaB-crystallin. Nature. 2013;494:90-4.

24. Yan Y, Jiang W, Liu L, Wang X, Ding C, Tian Z, Zhou R. Dopamine controls systemic inflammation through inhibition of NLRP3 inflammasome. Cell. 2015;160:62-73.

25. Oehlers SH, Flores MV, Hall CJ, Wang L, Ko DC, Crosier KE, Crosier PS. A whole animal chemical screen approach to identify modifiers of intestinal neutrophilic inflammation. FEBS J. 2017;284:402-13.

26. Tolstanova G, Deng X, Ahluwalia A, Paunovic B, Prysiazhniuk A, Ostapchenko L, Tarnawski A, Sandor Z, Szabo S. Role of Dopamine and D2 Dopamine Receptor in the Pathogenesis of Inflammatory Bowel Disease. Dig Dis Sci. 2015;60:2963-75.

27. Khan OA, Olek MJ. Treatment of paroxysmal symptoms in multiple sclerosis with bromocriptine. J Neurol Neurosurg Psychiatry. 1995;58:253.

28. Dijkstra C, Rouppe Van der Voort E, De Groot C, Huitinga I, Uitdehaag B, Polman C, Berkenbosch F. Therapeutic effect of the D2-Dopamine agonist Bromocriptine on acute and Relapsing Experimental Allergic Encephalomyelitis. Psychoneuroendocrinology. 1994;19:8.

29. Gonzalez H, Contreras F, Prado C, Elgueta D, Franz D, Bernales S, Pacheco R. Dopamine Receptor D3 Expressed on CD4 + T Cells Favors Neurodegeneration of Dopaminergic Neurons during Parkinson's Disease. J Immunol. 2013;190:5048-56.

30. Elgueta D, Aymerich MS, Contreras F, Montoya A, Celorrio M, Rojo-Bustamante E, Riquelme E, González H, Vásquez M, Franco R, Pacheco R. Pharmacologic antagonism of dopamine receptor D3 attenuates neurodegeneration and motor impairment in a mouse model of Parkinson's disease. Neuropharmacology. 2017;113:110-23.

31. Elgueta D, Contreras F, Prado C, Montoya A, Ugalde V, Chovar O, Villagra R, Henriquez C, Abellanas MA, Aymerich MS, et al. Dopamine Receptor D3 Expression Is Altered in CD4(+) T-Cells From Parkinson's Disease Patients and Its Pharmacologic Inhibition Attenuates the Motor Impairment in a Mouse Model. Front Immunol. 2019;10:981. 
32. Gonzalez H, Elgueta D, Montoya A, Pacheco R. Neuroimmune regulation of microglial activity involved in neuroinflammation and neurodegenerative diseases. J Neuroimmunol. 2014;274:1-13.

33. Contreras F, Prado C, Gonzalez H, Franz D, Osorio-Barrios F, Osorio F, Ugalde V, Lopez E, Elgueta D, Figueroa A, et al. Dopamine Receptor D3 Signaling on CD4 + T Cells Favors Th1- and Th17-Mediated Immunity. J Immunol. 2016;196:4143-9.

34. Ugalde V, Contreras F, Prado C, Chovar O, Espinoza A, Pacheco R. Dopaminergic signalling limits suppressive activity and gut homing of regulatory $\mathrm{T}$ cells upon intestinal inflammation. Mucosal Immunol 2020.

35. Wang W, Cohen JA, Wallrapp A, Trieu KG, Barrios J, Shao F, Krishnamoorthy N, Kuchroo VK, Jones MR, Fine A, et al. Age-Related Dopaminergic Innervation Augments T Helper 2-Type Allergic Inflammation in the Postnatal Lung. Immunity. 2019;51:1102-18 e1107.

36. Osorio-Barrios F, Prado C, Contreras F, Pacheco R. Dopamine Receptor D5 Signaling Plays a Dual Role in Experimental Autoimmune Encephalomyelitis Potentiating Th17-Mediated Immunity and Favoring Suppressive Activity of Regulatory T-Cells. Front Cell Neurosci. 2018;12:192.

37. Prado C, Gaiazzi M, Gonzalez H, Ugalde V, Figueroa A, Osorio-Barrios FJ, Lopez E, Lladser A, Rasini E, Marino F, et al. Dopaminergic Stimulation of Myeloid Antigen-Presenting Cells Attenuates Signal Transducer and Activator of Transcription 3-Activation Favouring the Development of Experimental Autoimmune Encephalomyelitis. Front Immunol. 2018;9:571.

38. Prado C, Contreras F, Gonzalez H, Diaz P, Elgueta D, Barrientos M, Herrada AA, Lladser A, Bernales S, Pacheco R. Stimulation of dopamine receptor D5 expressed on dendritic cells potentiates Th17mediated immunity. J Immunol. 2012;188:3062-70.

39. Prado C, Bernales S, Pacheco R. Modulation of T-cell Mediated Immunity by Dopamine Receptor D5. Endocrine Metabolic Immune Disorders - Drug Targets. 2013;13:11.

40. Balkowiec-Iskra E, Kurkowska-Jastrzebska I, Joniec I, Ciesielska A, Czlonkowska A, Czlonkowski A. Dopamine, serotonin and noradrenaline changes in the striatum of C57BL mice following myelin oligodendrocyte glycoprotein (MOG) 35-55 and complete Freund adjuvant (CFA) administration. Acta Neurobiol Exp (Wars). 2007;67:379-88.

41. Cosentino M, Zaffaroni M, Trojano M, Giorelli M, Pica C, Rasini E, Bombelli R, Ferrari M, Ghezzi A, Comi G, et al. Dopaminergic modulation of CD4 + CD25(high) regulatory T lymphocytes in multiple sclerosis patients during interferon-beta therapy. Neuroimmunomodulation. 2012;19:283-92.

42. Marino F, Cosentino M. Multiple sclerosis: Repurposing dopaminergic drugs for MS-the evidence mounts. Nat Rev Neurol. 2016;12:191-2.

43. Balkowiec-Iskra E, Kurkowska-Jastrzebska I, Joniec I, Ciesielska A, Muszynska A, Przybylkowski A, Czlonkowska A, Czlonkowski A. MPTP-induced central dopamine depletion exacerbates experimental autoimmune encephalomyelitis (EAE) in C57BL mice. Inflamm Res. 2007;56:311-7.

44. Montoya A, Elgueta D, Campos J, Chovar O, Falcon P, Matus S, Alfaro I, Bono MR, Pacheco R. Dopamine receptor D3 signalling in astrocytes promotes neuroinflammation. J Neuroinflammation. 2019;16:258. 
45. Elgueta D, Aymerich MS, Contreras F, Montoya A, Celorrio M, Rojo-Bustamante E, Riquelme E, Gonzalez H, Vasquez M, Franco R, Pacheco R. Pharmacologic antagonism of dopamine receptor D3 attenuates neurodegeneration and motor impairment in a mouse model of Parkinson's disease. Neuropharmacology. 2017;113:110-23.

46. McKenna F, McLaughlin P, Lewis B, Sibbring G, Cummerson J, Bowen-Jones D, Moots R. Dopamine receptor expression on human T- and B-lymphocytes, monocytes, neutrophils, eosinophils and NK cells: a flow cytometric study. j neuroimmunol. 2002;132:7.

47. Pacheco R. Targeting dopamine receptor D3 signalling in inflammation. Oncotarget. 2017;8:2.

48. Joseph; JD, Wang Y, Miles P, Budygin E, Picetti R, Gainetdinov R, Caron M, Wightman R. DOPAMINE AUTORECEPTOR REGULATION OF RELEASE AND UPTAKE IN MOUSE BRAIN SLICES IN THE ABSENCE OF D3 RECEPTORS. Neuroscience. 2002;112:11.

49. Moore C, Tejon G, Fuentes C, Hidalgo Y, Bono MR, Maldonado P, Fernandez R, Wood KJ, Fierro JA, Rosemblatt $\mathrm{M}$, et al. Alloreactive regulatory $\mathrm{T}$ cells generated with retinoic acid prevent skin allograft rejection. Eur J Immunol. 2015;45:452-63.

50. Fillatreau S, Sweenie CH, McGeachy MJ, Gray D, Anderton SM. B cells regulate autoimmunity by provision of IL-10. Nat Immunol. 2002;3:944-50.

51. Zheng Y, Yu M, Padmanabhan A, Aster RH, Yuan L, Wen R, Wang D. Critical role of CD4 T cells in PF4/heparin antibody production in mice. Blood. 2015;125:1826-9.

52. Obino D, Fetler L, Soza A, Malbec O, Saez JJ, Labarca M, Oyanadel C, Del Valle Batalla F, Goles N, Chikina A, et al. Galectin-8 Favors the Presentation of Surface-Tethered Antigens by Stabilizing the B Cell Immune Synapse. Cell Rep. 2018;25:3110-22 e3116.

53. Bettelli E, Sullivan B, Szabo SJ, Sobel RA, Glimcher LH, Kuchroo VK. Loss of T-bet, but not STAT1, prevents the development of experimental autoimmune encephalomyelitis. J Exp Med. 2004;200:7987.

54. Evans JG, Chavez-Rueda KA, Eddaoudi A, Meyer-Bahlburg A, Rawlings DJ, Ehrenstein MR, Mauri C. Novel suppressive function of transitional $2 \mathrm{~B}$ cells in experimental arthritis. J Immunol. 2007; 178:7868-78.

55. Kitamura D, Roes J, Kühn R, Rajewsky K. A B-cell deficient mouse by targeted disruption of the membrane exon of the immunoglobulin mu chain gene. Nature. 1991;350:4.

56. Codarri L, Gyulveszi G, Tosevski V, Hesske L, Fontana A, Magnenat L, Suter T, Becher B. RORgammat drives production of the cytokine GM-CSF in helper T cells, which is essential for the effector phase of autoimmune neuroinflammation. Nat Immunol. 2011;12:560-7.

57. Saraste M, Penttila TL, Airas L. Natalizumab treatment leads to an increase in circulating CXCR3expressing B cells. Neurol Neuroimmunol Neuroinflamm. 2016;3:e292.

58. Ruprecht CR, Lanzavecchia A. Toll-like receptor stimulation as a third signal required for activation of human naive B cells. Eur J Immunol. 2006;36:810-6.

59. Jegerlehner A, Maurer P, Bessa J, Hinton HJ, Kopf M, Bachmann MF. TLR9 signaling in B cells determines class switch recombination to IgG2a. J Immunol. 2007;178:2415-20. 
60. Rubtsova K, Rubtsov AV, Thurman JM, Mennona JM, Kappler JW, Marrack P. B cells expressing the transcription factor T-bet drive lupus-like autoimmunity. J Clin Invest. 2017;127:1392-404.

61. van Langelaar J, Rijvers L, Janssen M, Wierenga-Wolf AF, Melief MJ, Siepman TA, de Vries HE, Unger PA, van Ham SM, Hintzen RQ, van Luijn MM. Induction of brain-infiltrating T-bet-expressing B cells in multiple sclerosis. Ann Neurol. 2019;86:264-78.

62. Bettelli E, Baeten D, Jager A, Sobel RA, Kuchroo VK. Myelin oligodendrocyte glycoprotein-specific T and B cells cooperate to induce a Devic-like disease in mice. J Clin Invest. 2006;116:2393-402.

63. Krishnamoorthy G, Lassmann H, Wekerle H, Holz A. Spontaneous opticospinal encephalomyelitis in a double-transgenic mouse model of autoimmune T cell/B cell cooperation. J Clin Invest. 2006;116:2385-92.

64. Craft JE. Follicular helper T cells in immunity and systemic autoimmunity. Nat Rev Rheumatol. 2012;8:337-47.

65. Serre K, Cunningham AF, Coughlan RE, Lino AC, Rot A, Hub E, Moser K, Manz R, Ferraro A, Bird R, et al. CD8 $T$ cells induce T-bet-dependent migration toward CXCR3 ligands by differentiated $B$ cells produced during responses to alum-protein vaccines. Blood. 2012;120:4552-9.

66. Matsushita T, Horikawa M, Iwata Y, Tedder TF. Regulatory B cells (B10 cells) and regulatory T cells have independent roles in controlling experimental autoimmune encephalomyelitis initiation and late-phase immunopathogenesis. J Immunol. 2010;185:2240-52.

67. Matsumoto M, Baba A, Yokota T, Nishikawa H, Ohkawa Y, Kayama H, Kallies A, Nutt SL, Sakaguchi S, Takeda K, et al. Interleukin-10-producing plasmablasts exert regulatory function in autoimmune inflammation. Immunity. 2014;41:1040-51.

68. Yednock TA, Cannon C, Fritz LC, Sanchez-Madrid F, Steinman L, Karin N. Prevention of experimental autoimmune encephalomyelitis by antibodies against alpha 4 beta 1 integrin. Nature. 1992;356:4.

69. Lehmann-Horn K, Sagan SA, Bernard CC, Sobel RA, Zamvil SS. B-cell very late antigen-4 deficiency reduces leukocyte recruitment and susceptibility to central nervous system autoimmunity. Ann Neurol. 2015;77:7.

70. Glatigny S, Wagner CA, Bettelli E. Cutting Edge: Integrin alpha4 Is Required for Regulatory B Cell Control of Experimental Autoimmune Encephalomyelitis. J Immunol. 2016;196:3542-6.

71. Lublin F, Cutter G, Giovannoni G, Pace A, Campbell N, Belachew S. Natalizumab reduces relapse clinical severity and improves relapse recovery in MS. Multiple Sclerosis Related Disorders. 2014;3:7.

72. Basova L, Najera JA, Bortell N, Wang D, Moya R, Lindsey A, Semenova S, Ellis RJ, Marcondes MCG. Dopamine and its receptors play a role in the modulation of CCR5 expression in innate immune cells following exposure to Methamphetamine: Implications to HIV infection. PLoS One. 2018;13:e0199861.

73. Espinosa-Oliva AM, de Pablos RM, Sarmiento M, Villaran RF, Carrillo-Jimenez A, Santiago M, Venero $\mathrm{JL}$, Herrera AJ, Cano J, Machado A. Role of dopamine in the recruitment of immune cells to the nigrostriatal dopaminergic structures. Neurotoxicology. 2014;41:89-101. 
74. Watanabe Y, Nakayama T, Nagakubo D, Hieshima K, Jin Z, Katou F, Hashimoto K, Yoshie O. Dopamine selectively induces migration and homing of naive CD8 $+\mathrm{T}$ cells via dopamine receptor D3. J Immunol. 2006;176:9.

75. Kipnis J, Cardon M, Avidan H, Lewitus GM, Mordechay S, Rolls A, Shani Y, Schwartz M. Dopamine, through the extracellular signal-regulated kinase pathway, downregulates CD4 + CD25 + regulatory Tcell activity: implications for neurodegeneration. J Neurosci. 2004;24:6133-43.

\section{Figures}

A
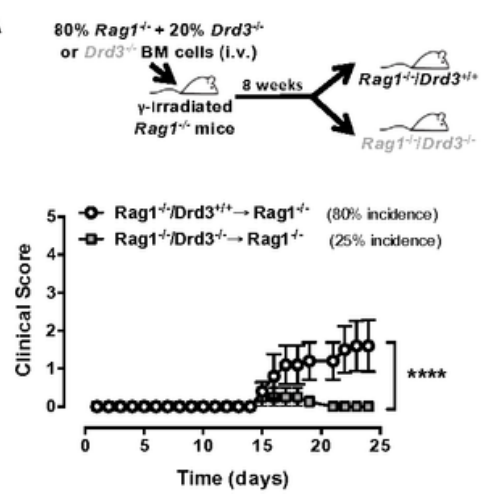

C

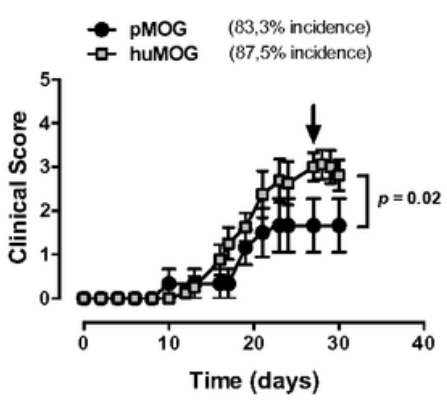

B
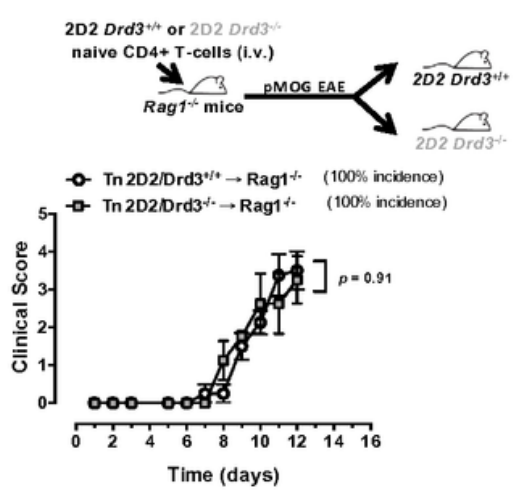

D

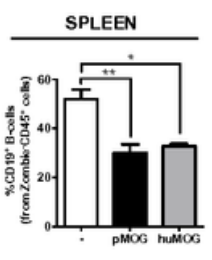

(dens)

E
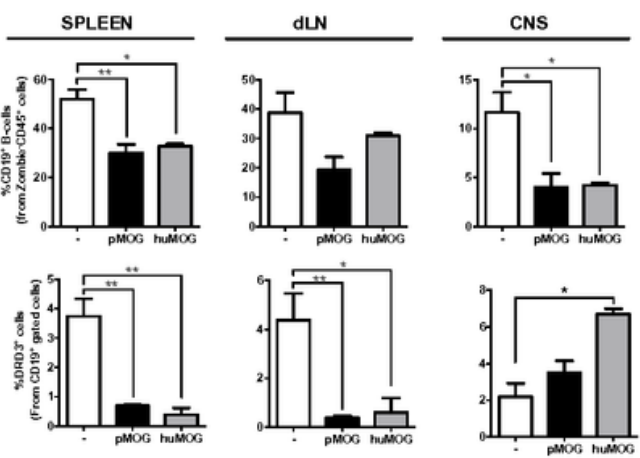

Figure 1. Prado et al.

\section{Figure 1}

DRD3-signalling in lymphocytes is required for the development of CNS-autoimmunity. (A) BM chimeric mice harbouring Drd3-deficient or Drd3-sufficient lymphocytes were generated by the i.v. transfer of a 4:1 mixed BM from Rag1-/- and Drd3-/- mice (grey symbols) or 4:1 mixed BM from Rag1-/- and Drd3+/+ mice (white symbols) respectively into $y$-irradiated Rag1-/- recipient mice. Afterwards, EAE was induced in 
chimeric mice by immunization with pMOG35-55 in CFA followed by pertussis toxin injection and disease severity was determined throughout the time-course of the disease development. $n=4-5$ mice per group. Top panel shows an illustration of the experimental strategy for generation of chimeric mice. Bottom panel shows the quantification of clinical score for different experimental groups. (B) Primary progressive EAE was induced in mice bearing Drd3-deficient (grey symbols) or Drd3-sufficient (white symbols) CD4+ T-cells by the i.v. transfer of transgenic naïve CD4+ T-cells ( $T n ; 7,5 \times 105$ cells per mouse) isolated from Drd3-/-2D2 or Drd3+/+ 2D2 mice into Rag1-/- recipient mice. Disease severity was determined throughout the time-course of the disease development. $n=4$ mice per group. Top panel illustrates the experimental design to induce primary progressive EAE. Bottom panel shows the quantification of clinical score for different experimental groups. (C) EAE was induced in wild-type C57BL/ 6 mice by immunization with pMOG35-55 (black symbols) or huMOG (grey symbols) in CFA followed by pertussis toxin injection. Disease severity was evaluated throughout the time-course of the disease development. $n=6-8$ mice per group. (D and E) At the peak of disease severity (indicated by an arrow in C), mononuclear cells were isolated from the spleen, draining lymph nodes (dLN) and central nervous system (CNS) and the frequency of CD19+ B-cells from the CD45+ gate (D) and the percentage of DRD3 expression in CD19+ Bcells (E) were evaluated. A control group (white bars) without immunization (-) was included in the analysis. Data representative from one out of three independent experiments is shown. (A-E) Values represent mean \pm SEM. *, $p<0.05 ;{ }^{* *}, p<0.01 ; * \star \star *, p<0.0001$ by Mann-Whitney $U$ test $(A-C)$ or unpaired Student's t-test (D-E). 
Figure 2. Prado et al.
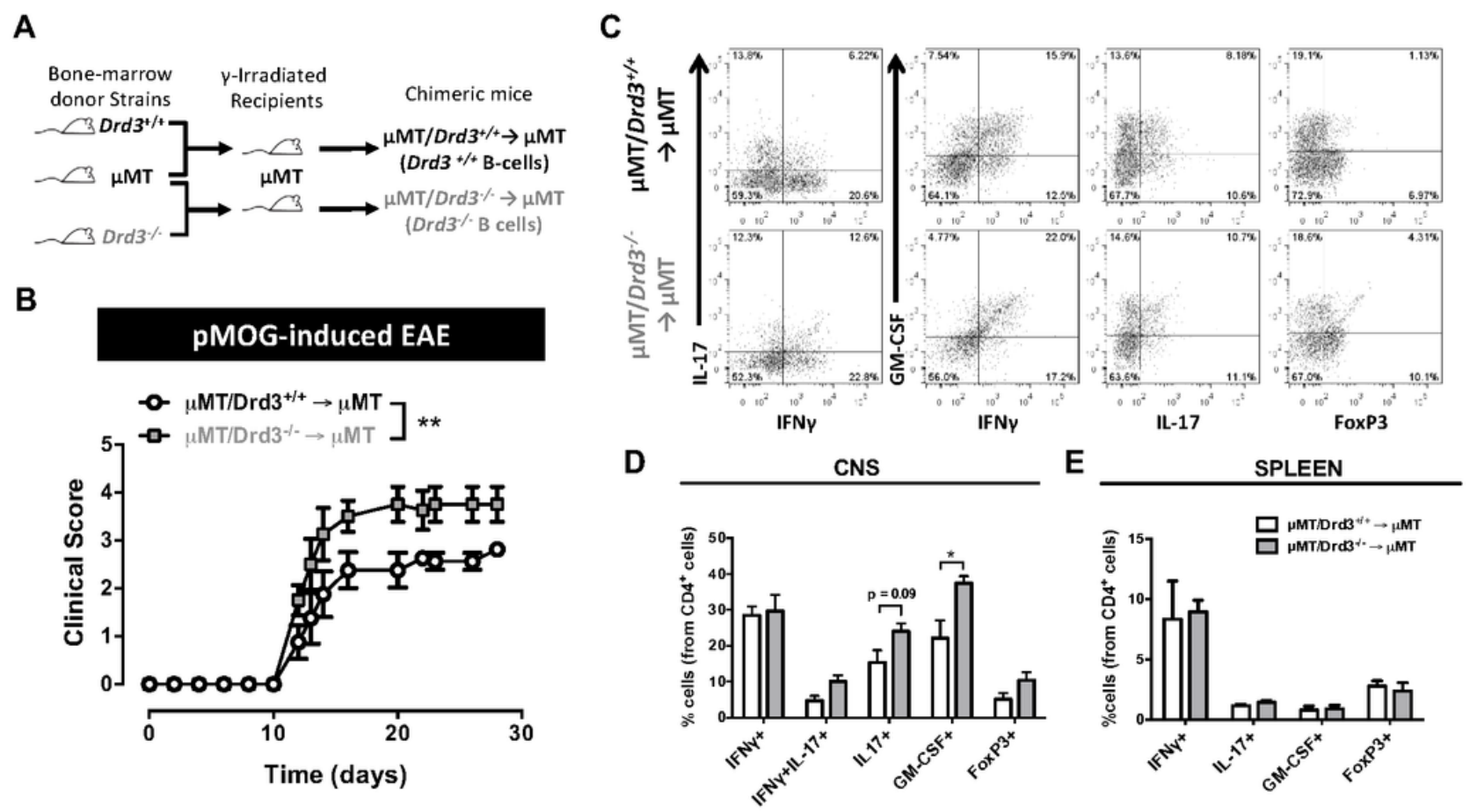

Figure 2

DRD3-signalling in B-cells attenuates disease severity in an EAE model that does not depend on the APCfunction of B-cells. BM chimeric mice harbouring Drd3-deficient or Drd3-sufficient B-cells were generated by the i.v. transfer of a 4:1 mixed BM from $\mu \mathrm{MT}$ and Drd3-/- mice (grey symbols) or 4:1 mixed BM from $\mu \mathrm{MT}$ and Drd3+/+ mice (black symbols) respectively into $\gamma$-irradiated $\mu \mathrm{MT}$ recipient mice. (A) Schematic illustration of chimeric mice generation. (B-E) EAE was induced in chimeric mice by immunization with pMOG35-55 in CFA followed by pertussis toxin injection. $\mathrm{n}=8$ mice per group. (B) Disease severity was evaluated throughout the time-course of the disease development. (C-E) At the peak of disease severity (day 15 post-induction), mononuclear cells were isolated from the CNS (C and D) and the spleen (E) followed by ex vivo stimulation with PMA/ionomycin in the presence of brefeldin A, and intracellular cytokine staining analysis in CD4+ T-cells was carried out by flow cytometry. (C) Representative dot-plots in the CD4+ gate are shown. Numbers indicate the percentage of cells in the corresponding quadrant. (D and E) Quantification of the frequency of CD4+ T-cells producing IFNy, IL-17, GM-CSF or expressing FoxP3. Data representative from one out of three independent experiments is shown. (B, D and E) Values 
represent the mean \pm SEM. *, $p<0.05 ;{ }^{* *}, p<0.01$; by Mann-Whitney U test $(B)$ or unpaired Student's t-test (D-E).

Figure 3. Prado et al.

A

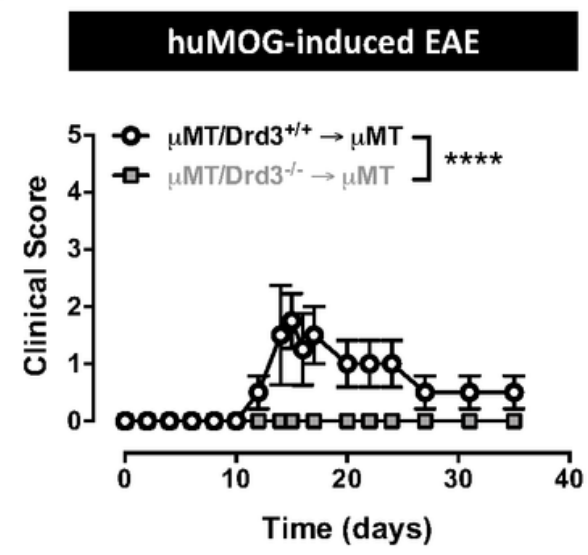

B

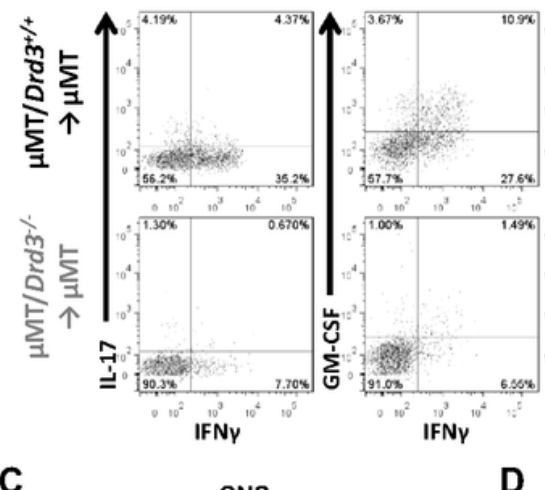

C

CNS

D

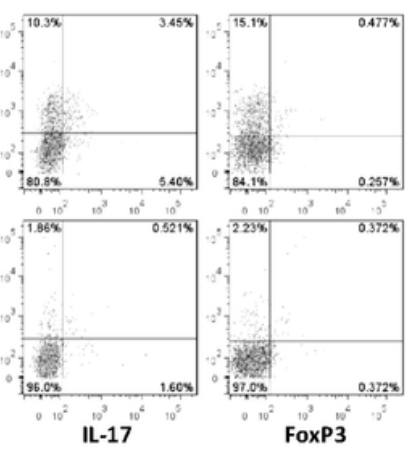

SPLEEN
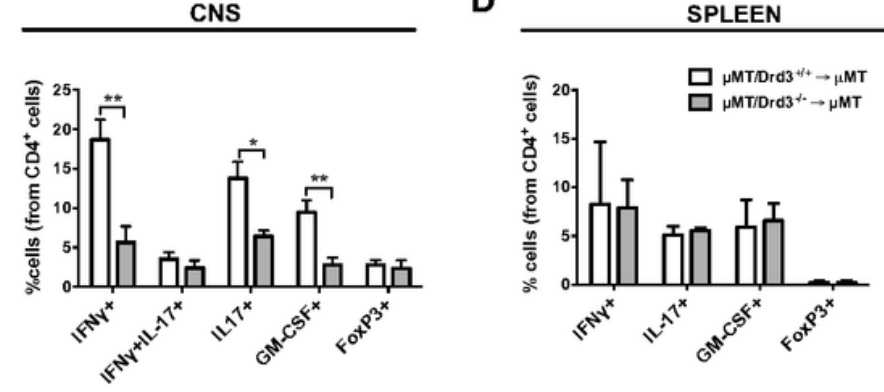

\section{Figure 3}

Drd3-deficiency in B-cell abrogates disease manifestation in an EAE model that depends on the APCfunction of B-cells. BM chimeric mice harbouring Drd3-deficient (grey symbols) or Drd3-sufficient (black symbols) B-cells were generated as described in figure 2A. Afterwards, EAE was induced in chimeric mice by immunization with huMOG in CFA followed by pertussis toxin injection. $n=4$ mice per group. (A) Disease severity was evaluated throughout the time-course of the disease development. (B-D) At the peak of disease severity (day 15 post-induction), mononuclear cells were isolated from the CNS (B and $C$ ) and the spleen (D) followed by ex vivo stimulation with PMA/ionomycin in the presence of brefeldin $A$, and intracellular cytokine staining analysis in CD4+ T-cells was carried out by flow cytometry. (B) Representative dot-plots in the CD4+ gate are shown. Numbers indicate the percentage of cells in the corresponding quadrant. ( $C$ and D) Quantification of the frequency of CD4+ T-cells producing IFNY, IL-17, GM-CSF or expressing FoxP3. Data representative from one out of three independent experiments is 
shown. (A-D) Values represent the mean \pm SEM. *, $p<0.05 ; * \star, p<0.01 ; * \star \star \star, p<0.0001$ by Mann-Whitney U test $(A)$ or unpaired Student's t-test (C-D).

Figure 4. Prado et al.

A

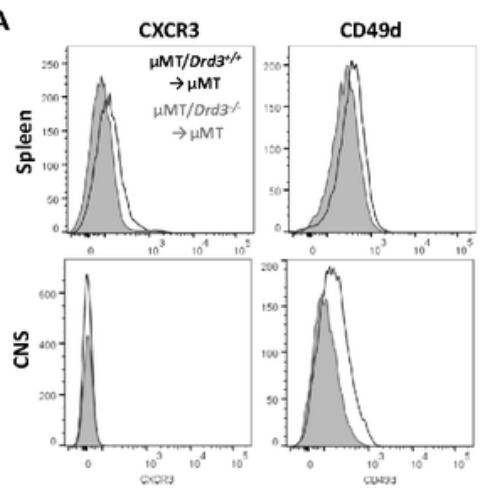

D

$\mathbf{E}$

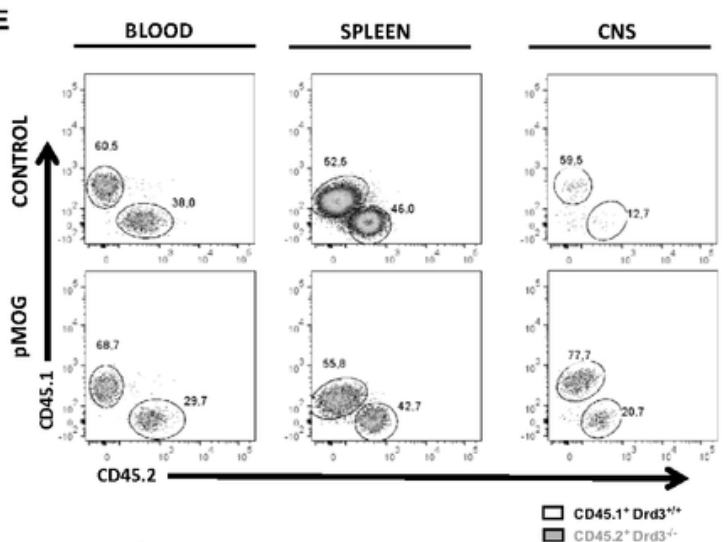

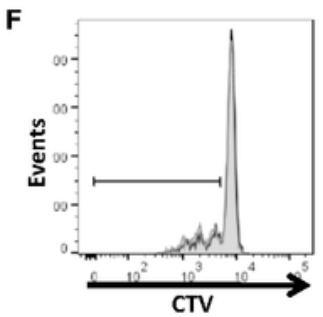

G

C
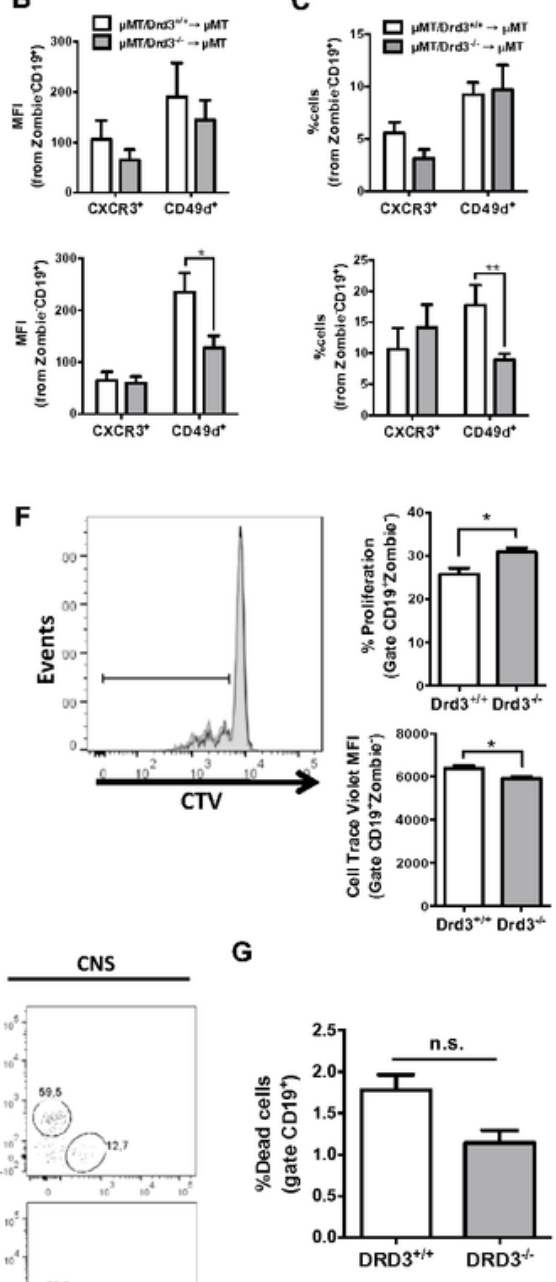

H

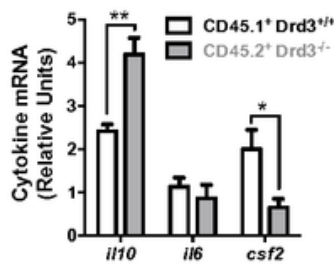

Figure 4

DRD3-signalling favours the expression of a4-integrin and attenuates the immunosuppressive profile in Bcells infiltrating the CNS in an EAE model that does not depend on the APC-function of B-cells. (A-C) BM chimeric mice harbouring Drd3-deficient (grey symbols) or Drd3-sufficient (white symbols) B-cells were 
generated as described in figure 2A. Afterwards, EAE was induced in chimeric mice by immunization with pMOG35-55 in CFA followed by pertussis toxin injection. $n=6-9$ mice per group. At the peak of disease severity (day 15 post-induction), mononuclear cells were isolated from the spleen and the CNS and the surface expression of CXCR3 and a4 integrin (CD49d) were analysed in the CD19+ population by flow cytometry. (A) Representative histograms for the expression of CXCR3 and CD49d in the CD19+ cells are shown. (B) Quantification of the mean fluorescence intensity (MFI) associated to the surface expression of CXCR3 and CD49d in living (ZAq-) CD19+ cells isolated from the spleen (top panel) and CNS (bottom panel). (C) Quantification of the percentage of surface expression of CXCR3 and CD49d in living (ZAq-) CD19+ cells isolated from the spleen (top panel) and CNS (bottom panel). (B-C) Values represent the mean \pm SEM. *, $p<0.05$; **, $p<0.01$ by unpaired Student's t-test. (D-E) BM chimeric mice harbouring Drd3deficient and Drd3-sufficient B-cells were generated by the i.v. transfer of a 1:1 mixed BM from Cd45.1+/+/Cd45.2-/-/Drd3+/+ mice (white symbols) and Cd45.1-/-/Cd45.2+/+//Drd3-/- mice (grey symbols) into $\gamma$-irradiated $\mu \mathrm{MT}$ recipient mice. Afterwards, EAE was induced in chimeric mice by immunization with pMOG35-55 in CFA followed by pertussis toxin injection. $\mathrm{n}=8$ mice per group. (D) Schematic illustration of the experimental design. (E) At the peak of disease severity (day 15 postinduction), mononuclear cells were isolated from peripheral blood (left panel), the spleen (middle panel) and the CNS (right panel) and the frequency of total CD19+ B-cells was analysed by flow cytometry. Top panels show representative dot-plots of CD45.1+ versus CD45.2+ cells in the CD19+ gate. Numbers indicate the percentage of cells in the corresponding region. Bottom panels show the percentage quantification. Values represent the mean \pm SEM from three to five determinations. Data representative from one out of three independent experiments is shown. *. $P<0.05 ; * \star, p<0.01$, $* \star \star *, p<0.0001$ by two-way ANOVA followed by Sidak's post-hoc test. (F-G) Naïve B-cells (CD19+ IgDhi IgMint CD11c- TCRß-) were isolated from the spleen of Drd3-deficient (grey bars/histograms) or Drd3-sufficient (white bars/histograms) mice by cell-sorting, loaded with cell-trace violet (CTV) and incubated in vitro in the presence of anti-CD40, anti-IgM, IFNY and the TLR9-ligand CpG for 5 days. (F) The extent of proliferation was evaluated as the dilution of the fluorescence associated to CTV in living (ZAq-) CD19+ cells by flow cytometry. Representative histograms are shown in the left panel. The marker indicates cells displaying dilution of CTV-associated fluorescence. Quantification of the percentage of cells displaying diluted CTVassociated fluorescence (top right panel) and the MFI of CTV-associated fluorescence (bottom right panel) are shown. (G) The extent of cell dead was determined as the percentage of ZAq+ cells in the CD19+ gate. $(F-G)$ Values represent the mean \pm SEM from three determinations. ${ }^{*}, p<0.05$ by unpaired two-tailed Student's t-test. n.s. non-significant. $(H)$ Chimeric mice were treated as shown in (D) and at the peak of disease severity (day 15 post-induction), CD19+ B-cells were isolated from the spleen and the levels of cytokine transcripts was analysed by qRT-PCR. The levels of gapdh transcripts were used as a housekeeping. Data was obtained from 4-6 mice per group, which is representative from one out of three independent experiments. Values represent mean \pm SEM. ${ }^{*}, p<0.05 ;{ }^{*}, p<0.01$ by unpaired Student's t-test. 

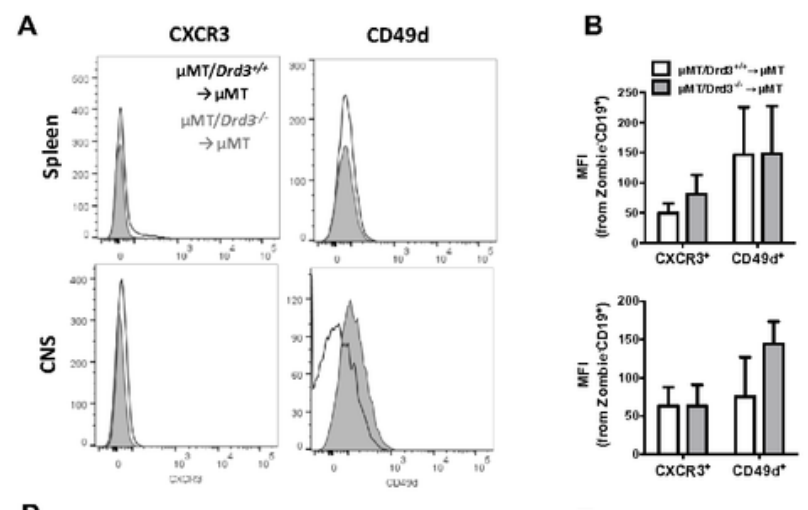

C

Figure 5. Prado et al.
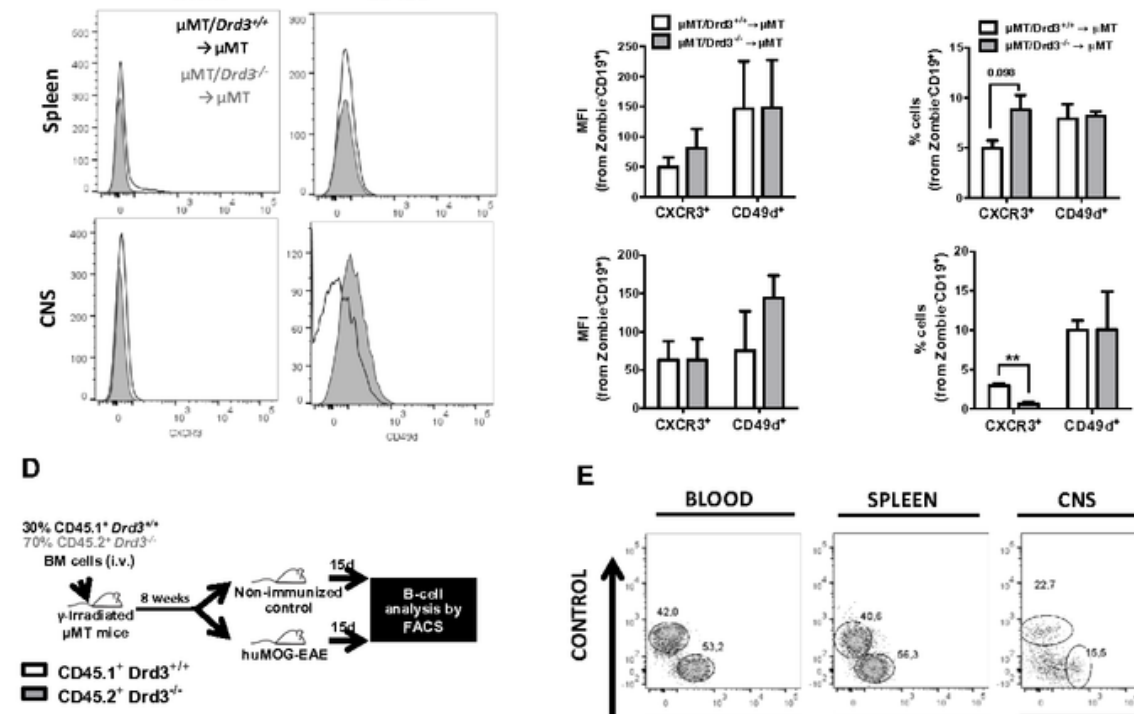

$\mathbf{F}$
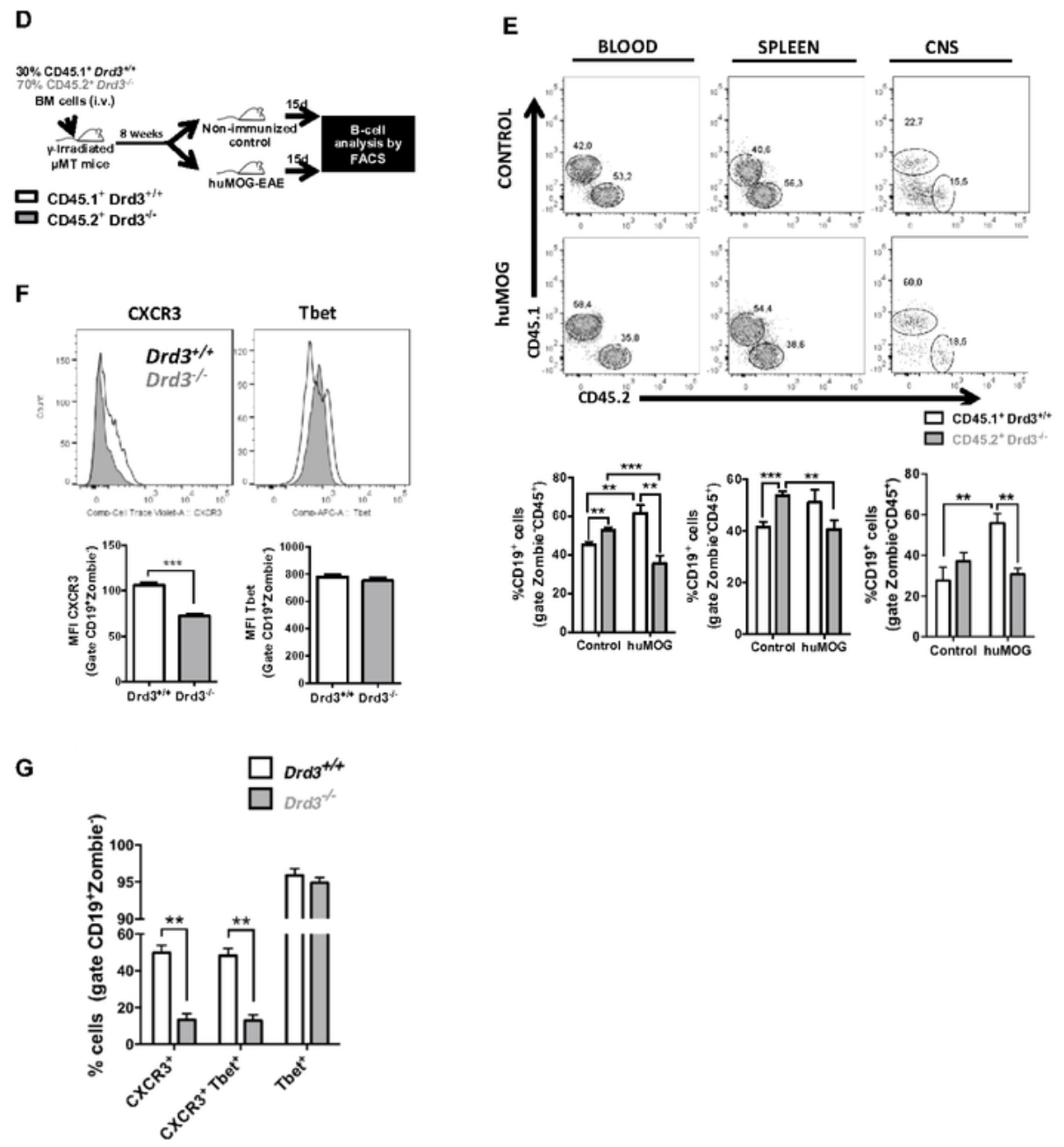

\section{Figure 5}

Drd3-deficiency in B-cells impairs the acquisition of CXCR3 and their infiltration into the CNS in an EAE model that depends on the APC-function of B-cells. (A-C) BM chimeric mice harbouring Drd3-deficient (grey symbols) or Drd3-sufficient (white symbols) B-cells were generated as described in figure 2A. Afterwards, EAE was induced in chimeric mice by immunization with huMOG in CFA followed by pertussis toxin injection. $n=3-6$ mice per group. At the peak of disease severity (day 15 post-induction), 
mononuclear cells were isolated from the spleen and the CNS and the surface expression of CXCR3 and a4 integrin (CD49d) were analysed in the CD19+ population by flow cytometry. (A) Representative histograms for the expression of CXCR3 and CD49d in the CD19+ cells are shown. Quantification of the MFI (B) and frequency (C) associated to the surface expression of CXCR3 and CD49d in living (ZAq-) CD19+ cells isolated from the spleen (top panel) and CNS (bottom panel). (B-C) Values represent the mean \pm SEM. **, $p<0.01$ by unpaired Student's t-test. (D-E) BM chimeric mice harbouring Drd3-deficient and Drd3-sufficient B-cells were generated by the i.v. transfer of a 3:7 mixed BM from

Cd45.1+/+/Cd45.2-/-/Drd3+/+ mice (white bars) and Cd45.1-/-/Cd45.2+/+/Drd3-/- mice (grey bars) into Y -irradiated $\mu \mathrm{MT}$ recipient mice. Afterwards, EAE was induced in chimeric mice by immunization with huMOG in CFA followed by pertussis toxin injection. (D) Schematic illustration of the experimental design. (E) At the peak of disease severity (day 15 post-induction), mononuclear cells were isolated from peripheral blood (left panels), the spleen (middle panels) and the CNS (right panels) and the frequency of total CD19+ B-cells was analysed by flow cytometry. Top panels show representative dot-plots of CD45.1+ versus CD45.2+ cells in the CD19+ gate. Numbers indicate the percentage of cells in the corresponding region. Bottom panels show the percentage quantification. Values represent the mean \pm SEM from 4-8 mice per group. Data representative from one out of three independent experiments is shown. ${ }^{*}, \mathrm{p}<0.01$, $* \star \star, p<0.001$ by two-way ANOVA followed by Sidak's post-hoc test. ( $\mathrm{F}-\mathrm{G}$ ) Naïve B-cells (CD19+ IgDhi IgMint CD11C- TCR $\beta$-) were isolated from the spleen of Drd3-deficient (grey histograms/bars) or Drd3-sufficient (white histograms/bars) mice by cell-sorting and incubated in vitro in the presence of anti-CD40, anti-IgM, IFNY and the TLR9-ligand CpG. After 5 days, CXCR3 and Tbet expression were evaluated by flow cytometry. (F) Representative histograms of CXCR3 and Tbet expression in the CD19+ population are shown in top panels. Quantification of the mean fluorescence intensity (MFI) associated to CXCR3 (bottom left panel) and Tbet (bottom right panel) are shown. (G) Quantification of the percentage (left panel) and absolute number (right panel) of CD19+ B-cells positive for CXCR3, Tbet or both are shown. (F-G) Values represent the mean \pm SEM from three determinations. **, $p<0.01 ; * \star \star, p<0.001 ; * \star \star \star, p<0.0001$ by unpaired two-tailed Student's t-test.

\section{Supplementary Files}

This is a list of supplementary files associated with this preprint. Click to download.

- Supplementarymaterial8abr2021.pdf 